\title{
The initiation and development of metamorphic foliation in the Otago Schist, Part 2: Evidence from quartz grain-shape data
}

\author{
AARON STALLARD, ${ }^{1}$ DAVID SHELLEY ${ }^{1}$ AND STEVE REDDY ${ }^{2}$ \\ ${ }^{1}$ Department of Geological Sciences, University of Canterbury, Private Bag 4800, Christchurch, \\ New Zealand (aaron.stallard@canterbury.ac.nz) \\ ${ }^{2}$ Tectonics Special Research Centre, Dept. of Applied Geology, Curtin University of Technology, \\ Perth, WA 6845, Australia
}

\begin{abstract}
Shape, size and orientation measurements of quartz grains sampled along two transects that cross zones of increasing metamorphic grade in the Otago Schist, New Zealand, reveal the role of quartz in the progressive development of metamorphic foliation. Sedimentary compaction and diagenesis contributed little to forming a shape preferred orientation (SPO) within the analysed samples. Metamorphic foliation was initiated at sub-greenschist facies conditions as part of a composite $\mathrm{S}_{1^{-}}$ bedding structure parallel to the axial planes of tight to isoclinal $F_{1}$ folds. An important component of this foliation is a pronounced quartz SPO that formed dominantly by the effect of dissolutionprecipitation creep on detrital grains in association with $\mathrm{F}_{1}$ strain. With increasing grade, the following trends are evident from the SPO data: (i) a progressive increase in the aspect ratio of grains in sections parallel to lineation, and the development of blade-shaped grains; (ii) the early development of a strong shape preferred orientation so that blade lengths define the linear aspect of the foliation (lineation) and the intermediate axes of the blades define a partial girdle about the lineation; (iii) a slight thinning and reduction in volume of grains in the one transect; (iv) an actual increase in thickness and volume in the survivor grains of the second transect. The highest-grade samples within the chlorite zone of the greenschist facies record segregation into quartz-rich and mica-rich layers. This segregation marks a key change in the distribution, deformation and SPO of the quartz grains. The contribution of quartz SPO to defining the foliation lessens as the previously discrete and aligned detrital quartz grains are replaced by aggregates and layers of dynamically recrystallised quartz grains of reduced aspect ratio and reduced alignment. Pressure solution now affects the margins of quartz-rich layers rather than individual grains. In higher-grade samples, therefore, the rock structure is characterised increasingly by segregation layering parallel to a foliation defined predominantly by mica SPO.
\end{abstract}

Key words: EBSD; foliation; Otago Schist; quartz; shape preferred orientation

\section{INTRODUCTION}

The origin and significance of metamorphic foliation is a topic of fundamental interest to structural and metamorphic geologists. In order to understand the origin and development of foliation, it is crucial to appreciate the nature of grain SPOs (e.g. Rivers \& Fyson, 1977; Ildefonse et al., 1990; Yassaghi et al., 2000; Stallard \& Shelley, in press), and SPO studies are important in understanding the history of structural development of metamorphic rocks as well as the deformation mechanisms by which strain was accumulated (e.g. Shelley, 1995; Mulchrone, 2002). In this paper we use 
foliation in terms of the shape preferred orientation (SPO) of the constituent mineral grains of a rock (Nicolas \& Poirier, 1976, p.305; Shelley, 1993, p.418). Despite the fact that it is SPO, not the lattice preferred orientation (LPO), that fundamentally defines foliation, relatively few studies have attempted to describe SPO development by documenting trends across metamorphic and deformational gradients (e.g. Rivers \& Fyson, 1977; Yassaghi et al., 2000; Stallard \& Shelley, in press). Studies that include data for SPO in 3-dimensions are also limited in number (e.g. Shelley, 1979; Miyake, 1993; Sawaguchi \& Ishii, 2003). The scarcity of SPO studies is especially true of quartz, despite the almost ubiquitous presence of large volumes of quartz in foliated metamorphic rocks of all grades.

The aim of this study is to investigate the contribution of quartz in defining metamorphic foliation, and the changing trends of quartz SPO with increasing metamorphic grade. In this study we document the changing patterns of shape, size and SPO of quartz grains with increasing metamorphic grade within the low grade Otago Schist, New Zealand, and these data are then discussed in relation to possible mechanisms leading to quartz orientation, the contribution of quartz in defining foliation, and the change of deformation mechanisms with increasing grade and increasing strain. The progressive development of foliation is reconstructed by sampling across zones of increasing metamorphic grade and employing the concept of 'space-for-time' substitution, whereby we assume that the SPO trends measured with increasing metamorphic grade approximate the changes that occur in a single body of rock subject to progressive metamorphism. The Otago schist is ideal for this type of study, because it is a largely intact metamorphic belt of relatively uniform bulk composition that preserves a continuous progression from non-metamorphic parent rock through increasing metamorphic grade and structural complexity to multiply folded and schistose greenschist facies (mainly chlorite zone) equivalents.

This study follows from an earlier paper (Stallard \& Shelley, in press) that interpreted the development of the white mica SPO in the Otago Schist as the result of competitive anisotropic growth of blade-shaped grains parallel to the extension direction during deformation.

\section{REGIONAL GEOLOGY AND SAMPLE TRANSECTS}

The Otago Schist is a $150 \mathrm{~km}$ wide NW-SE trending belt of prehnite-pumpellyite to greenschist facies schist (Fig. 1) derived from at least two sedimentary terranes. The SW portion of the schist is derived from volcaniclastic sediments of the Caples terrane, while the NE portion, which is that sampled in this study, is derived from a monotonous series of mainly granitoid-derived quartzofeldspathic mudstone and sandstone of the Permian to Triassic Torlesse terrane. The schist can be traced laterally into non-metamorphosed equivalents on both the NE (Torlesse) and SW (Caples) margins of the schist belt, and the boundary between Torlesse-derived and Caples-derived schist has been constrained by geochemical means within the core of the schist belt (Fig. 1a; Mortimer \& Roser, 1992). Mortimer (1993a,b) provides a useful summary of data on the structure and metamorphism of the Otago Schist.

Earlier workers divided the Otago Schist into textural zones as a means of mapping variation within the monotonous low-grade schists (see Fig. 1), mainly on the basis of the progressive development of metamorphic foliation and segregation layering, and the increasing thickness of metamorphic white mica grains (Turner, 1935; Turnbull et al., 2001).

$\mathrm{K}$-Ar dating of metamorphic mica suggests peak metamorphism, related to juxtaposition of the Caples and Torlesse terranes, occurred during the Jurassic (Nishimura et al., 2000; Little et al., 1999; Gray \& Foster, 2004), and the schist belt was exhumed during mid-Cretaceous tectonic extension (Forster \& Lister, 2003; Gray \& Foster, 2004). Peak metamorphic conditions in the 
highest-grade portions of the schist belt are estimated to have been $350-400^{\circ} \mathrm{C}$ and $8-10 \mathrm{~kb}$, although accurate thermobarimetric analysis is hampered by the lack of suitable mineral assemblages (Mortimer, 2000).

In this study, samples were collected from two transects across the NE (Torlesse) side of the Otago Schist (Fig. 1). Photomicrographs of representative quartz grains from samples of varying metamorphic grade are shown in Fig. 2, while a summary of structural and metamorphic trends along each transect can be found in Table 1. Dissolution-precipitation creep was the dominant mechanism of quartz deformation in lower grade parts of the transect (Fig. 2; see also Norris \& Bishop, 1990), and was accompanied and eventually succeeded by intracrystalline plastic deformation and recrystallisation in higher-grade samples.

The Lake Hawea transect is a 10km section from sub-greenschist facies semi-schist in the east to schist of the chlorite zone (greenschist facies) in the west (Fig. 1c). The transect begins in rocks sedimentary in character and dominated by tight to isoclinal folded bedding $\left(\mathrm{F}_{1}\right.$; see Fig. 3 for summary of structural data). The foliation is subparallel to bedding and to the axial planes of $\mathrm{F}_{1}$ folds, and forms a composite bedding- $\mathrm{S}_{1}$ structure $\left(\mathrm{S}_{0} / \mathrm{S}_{1}\right)$. A deformed conglomerate in the lower grade parts records axial ratios of 1.9:4.75:9 (Norris \& Bishop, 1990). Further west in the section, a second phase of folding $\left(\mathrm{F}_{2}\right)$ is locally accompanied by a crenulation cleavage $\left(\mathrm{S}_{2}\right)$ that overprints the composite $S_{0} / S_{1}$. A pronounced mineral lineation is parallel to $F_{2}$ fold axes. Crenulation during $\mathrm{F}_{2}$ was not universally developed, and is most commonly developed in $\mathrm{F}_{2}$ fold hinges where the composite $S_{0} / S_{1}$ structure is at a large angle to the developing $S_{2}$. At the western end of the transect, $S_{2}$ is penetrative, and earlier structures such as $F_{1}$ folds, bedding, and $S_{1}$ are not recognisable. A late crenulation lineation $\left(\mathrm{L}_{3}\right)$ overprints the earlier structures. The mineral assemblage is dominated by quartz, white mica, albite, and chlorite, with minor titanite, stilpnomelane and epidote. Segregation layering increases in intensity in the higher grade samples. Norris \& Bishop (1990) attributed the development of segregation within the schist to three related processes: the rotation and disruption of early formed quartz and quartz-albite veins, the amalgamation of strain shadow overgrowths on clastic quartz and feldspar grains, and the development of mica-rich solution seams.

The Lindis Pass transect ranges from non-schistose sediments through weakly foliated metasediments to recrystallised schist along a $35 \mathrm{~km}$ section (Fig. 1d). The section is less well exposed than the Lake Hawea section, and has been disrupted by post-metamorphic faulting. Despite these shortcomings, the Lindis Pass transect provides continuity between schist and nonmetamorphic equivalents, and extends into higher grade rocks than the Lake Hawea section. The Lindis Pass transect begins in non-foliated sediments, which are deformed by $F_{1}$ folds and a related $\mathrm{S}_{0}-\mathrm{S}_{1}$ composite foliation. This foliation is overprinted at the higher grade end of the transect by $\mathrm{F}_{2}$ folds and a crenulation cleavage. The metamorphic mineral assemblage includes quartz, albite, muscovite, chlorite, titanite, and minor ilmenite, with pumpellyite and prehnite in the subgreenschist facies part of the transect. The appearance of metamorphic chlorite marks the transition to Greenschist facies rocks part way along the transect (Fig. 1d). Detrital quartz, feldspar, muscovite, biotite, epidote, calcite and apatite are common, particularly in the lower-grade rocks.

\section{GRAIN SHAPE MEASUREMENTS}

\section{Methods}

Samples were collected from quartz-rich lithologies rather than mudstones and pelitic rocks, although in five samples, measurements were taken from both quartz-rich and mica-rich layers to determine if SPO trends were different between the contrasting lithologies. Two thin sections were cut perpendicular to foliation from each sample, one parallel to lineation and one perpendicular to 
lineation. Digital images were taken of a representative area of each section, and transferred to a personal computer. A $10 \times 12$ grid was superimposed upon each image, and the length, width and long axis orientation of the quartz grains nearest to each of the 120 grid points was measured. The number of grains measured in each sample depended upon grain size and density; the average was 76 grains per section. Length and orientation measurements were made using the graphics software CANVAS by drawing a line parallel to the grain length, or other dimension to be measured, and reading the length and orientation data from the software window. This method was suitable for measuring grains as small as 3 microns.

\section{Grain-shape data}

The grain shape data are summarised in Figs. 4 \& 5, and described in the following sections. Figure 4 presents grain shape data from individual samples along each transect, while Fig. 5 shows photomicrographs of samples, representative 3D grain shapes, and orientation data from four representative samples along each transect. Other representative photomicrographs of quartz grains from samples of increasing grade are shown in Fig. 2. In the following description of the data, trends are described in terms of increasing grade, from east to west of each transect, and this gradient also corresponds to increasing structural complexity.

\section{Aspect ratio}

In sections oriented parallel to lineation, the mean aspect ratio of quartz grains increases toward the higher-grade part of each transect, before decreasing again in the highest-grade samples (Fig. 4a,b). In the Lindis Pass transect, sections perpendicular to lineation record little variation in aspect ratio, with mean values remaining more or less constant at 2 to 1 as metamorphic grade increases. In the Lake Hawea transect, the aspect ratio in sections perpendicular to lineation decreases from 2.6 to 1.9 as metamorphic grade increases (Fig. 4b). Sections parallel to lineation consistently contain larger mean aspect ratios than sections oriented perpendicular to lineation (Fig. 4a,b).

\section{Grain length and thickness}

In this section, we use 'length' to describe the long axis of the 2D grain as measured in thin section, rather than the long axis of the 3D grain. The mean length and thickness of quartz grains increase substantially along most of the Lake Hawea transect, but there is a sudden and substantial decrease in the highest-grade sample (Fig. 4d). The Lindis Pass transect has a somewhat irregular trend (Fig. 4c), but unlike the Lake Hawea transect, the lengths and thicknesses of grains in sections perpendicular to lineation decrease overall except for a sudden and substantial increase in the highest grade sample (Fig. 4c). Grain lengths in sections parallel to lineation in the Lindis Pass rocks show an irregular variation, but overall, the mean grain volumes decrease slightly until the sudden increase at the highest grade.

In both transects, grain length is consistently greater in sections parallel to lineation than sections oriented perpendicular, whereas mean grain thickness is similar regardless of section orientation (Fig. 4c,d). The fact that thicknesses are similar in both sections is a good measure of the accuracy of the data. Within individual samples, the mean length of quartz grains is between 20 and $90 \%$ longer parallel to lineation compared with values measured from sections perpendicular to lineation (Fig. 4c,d). This geometry describes blade-shaped grains, with the plane of the blade 
defining the planar aspect of the foliation, and the length of the blade the lineation or linear aspect of the foliation.

The data presented graphically in Fig. 4 are summarised visually in Fig. 5, where idealised 3D grain shapes have been reconstructed to illustrate the changing trends in grain size and shape along the transects. The grain dimensions are derived from the mean thickness as measured in sections both parallel and perpendicular to lineation, and the mean lengths parallel and perpendicular to lineation. Grain shapes were constructed based on these values, and are represented as an ellipsoid fitted to the measured axes. Two idealised grains are presented for each sample that represent the $25^{\text {th }}$ and $75^{\text {th }}$ percentile measurements from the population of grains.

\section{Grain orientation}

In sections oriented parallel to lineation, quartz long axes are generally strongly aligned, and together with other minerals, especially the mica (Stallard \& Shelley, in press), define foliation. The distribution of grain orientations resembles a normal distribution (Fig. 5). An exception to this trend is the lowest grade (sedimentary) sample (sample 24/11-1), which contains a wide spread in the orientation of grains (Fig. 5e). The alignment of grains at first intensifies with increasing metamorphic grade, but then lessens in the highest grade samples of each transect (Fig. 5d,h). Grains with larger aspect ratios are more closely aligned to the plane of the mesoscopic foliation than grains with smaller aspect ratios (Fig. 5).

There exist pronounced differences between the recorded two-dimensional orientation and grain shape data in sections parallel to lineation versus those recorded in sections perpendicular to lineation (Fig. 6). It must be remembered that the two sections are simply two different twodimensional views of the three-dimensional SPO of the same grain population. The Otago Schists are typically SL-tectonites, and the stronger apparent alignment and higher aspect ratio of grains in sections parallel to the lineation are entirely predictable.

\section{Comparison of grain shapes from quartz-rich and mica-rich domains}

In order to test for differences in grain shape and size between the quartz-rich and mica-rich layers within individual samples, we measured shape and orientation data from both quartz-rich and micarich layers in 5 samples (LH1, LH4, LH10, LH11, LP11). An average of 71 quartz grains were sampled from both mica-rich and quartz-rich layers in each thin section, and the data averaged across all samples. Mean quartz aspect ratios are $27 \%$ greater in mica-rich domains compared with quartz-rich domains, and quartz grains from quartz-rich domains are larger, being 7\% longer and $46 \%$ greater in thickness than mean values from mica-rich domains from the same sample.

\section{Rare sigma-shaped quartz grains}

In one of the Lindis Pass specimens (LP8), numerous $\sigma$-shaped quartz grains occur (Fig. 7), and are geometrically similar to the common $\sigma$-shaped porphyoclasts of mylonites. It is clear with the ordinary polarising microscope that the Lindis Pass $\sigma$-shaped grains are detrital quartz clasts with overgrowths forming the "tails". The clasts typically have mica-rich solution seams on the two sides parallel to foliation, and asymmetric quartz tails and mica-beards on the other sides. The quartz tails are sometimes composite and interfingered with mica/chlorite. In some cases the crystallographic orientation of the quartz tail overgrowth is the same or similar to the host grain, but in other cases it is different. The sense of asymmetry, with one exception, is consistent throughout the specimen, and the quartz clasts and tails together define $\mathrm{C}-\mathrm{S}$ type structures, although the $\mathrm{C}$ planes might equally as 
well be interpreted as $C^{\prime}$ planes or extensional shears. In any case, the $\sigma$-shaped structures indicate that foliation development in this sample was associated with a degree of non-coaxial strain, as is typical for such shapes (Passchier \& Simpson, 1986).

Most $\sigma$-shaped grain structures described in the literature formed during dynamic recrystallisation, commonly under high differential stress, as in a mylonite. Formation of $\sigma$-shaped structures during dissolution-precipitation creep is less well known, but Bestmann et al. (2004) described $\sigma$-shaped quartz that developed during dissolution-precipitation creep within in a shear zone affecting greenschist facies marble from Thassos Island, Greece. The quartz grains they describe also display a quartz c-axes preferred orientation with c-axes preferentially aligned parallel to the shear direction. Stallard \& Shelley (1995), using samples from low-grade Paleozoic slates from New Zealand, showed that such a quartz LPO might develop by rigid rotation of quartz clasts during low grade metamorphic strain, and Bestmann et al. (2004) adopted this interpretation for the Thassos Island quartz LPO. In the Otago Schist samples we have not observed such a quartz LPO, and it may be that such fabrics develop less easily in the Torlesse greywacke-type lithologies of turbidite origin than in the more mature shelf facies sediments from which the Paleozoic NZ slates described by Stallard \& Shelley (1995) were derived.

Importantly, no $\delta$-shaped structures have been observed in the Lindis Pass or Lake Hawea specimens. This suggests little or no rotation of the "rigid" quartz clasts during strain and foliation formation. Indeed, elongate quartz clasts with long axes at a high angle to the foliation have well developed mica-beards and solution seams at their ends, yet have remained at a high angle to foliation with no evidence of rotation (Fig. 8).

\section{Quartz lattice orientation data}

In addition to the grain-shape measurements, analysis of quartz lattice orientation patterns were undertaken in order to complement the grain-shape data and provide additional constraints on the deformation mechanisms affecting quartz grains from samples of varying grade. Samples were analysed using electron back-scatter diffraction (EBSD) equipment housed at Curtin University, Perth, Australia.

\section{Methods}

Petrographic thin sections of five samples (24/11-1, LH1, LH25, LH10 and LP22) were mechanically polished to $0.25 \mu \mathrm{m}$ diamond paste using standard thin section polishing techniques. The samples were further polished using a $0.06 \mu \mathrm{m}$ colloidal silica suspension in a $\mathrm{NaOH}$ solution of pH10 on a Buehler Vibromet II polisher. Samples were mounted in a Phillips XL30 SEM and tilted to $70^{\circ}$. Crystal orientation mapping was undertaken by collecting electron backscatter patterns from the node points of a grid. At each node point the orientation of the crystal lattice was measured via the electron backscatter pattern (EBSP). Plotting orientation in this framework grid provides a crystallographic orientation map. Electron backscatter patterns were collected using an HKL Technology Nordlys detector. Each EBSP was analysed using HKL technology's Channel 5 software to determine orientation information for each analysis. This software was also used to generate orientation maps, plot stereographic projections of orientation data and calculate misorientation angles and axes of rotation between misoriented datum pairs. 


\section{Data}

Several different aspects of the quartz lattice orientation are derived from the EBSD data. Figure 9 shows the average intra-grain variation in lattice orientation for the six samples analysed. Detrital grains from sample 24/11-1 display internal strain features and relatively large variation in lattice orientation, but visible strain effects are relatively small in grains from low-grade foliated samples (LH1, LH25) and become more pronounced in higher-grade samples. Figure 10 shows a comparison of crystallographic orientation data from two deformed quartz grains that are typical of grains within each sample: a relatively undeformed grain from a low-grade sample (LH1), and a grain from a high-grade sample (LP22) that records greater deformation and variation in lattice orientation. The grain from sample LH1 shows just $3^{\circ}$ in intra-grain variation in lattice orientation, and crystal axes are of similar orientation throughout the grain (Fig. 10a-e). In contrast, a typical deformed grain from sample LP22 contains $15^{\circ}$ of intra-grain variation in lattice orientation (Fig. 10f-j). Strain in this grain involved rotation about the c-axis (Fig. 10g,j), and crystal axes record dispersion in orientation about the c-axis. Figure 11 shows quartz lattice preferred orientation patterns in samples of increasing grade. Only the highest-grade sample, LP22, shows a discernable pattern of c-axis orientations, with an oblique girdle pattern visible in the pole diagram at bottom left of Fig. 11.

\section{INTERPRETATIONS AND DISCUSSION}

\section{The evolution of quartz SPO with progressive metamorphism}

The degree to which individual grains contribute to foliation depends on their aspect ratio and SPO. Data collected in this study demonstrate that quartz SPO is an important component of the developing schistosity within the Otago Schist (Figs. 4 \& 5), although the contribution of quartz varies with metamorphic grade. The evolving patterns of quartz SPO can largely be explained by considering the deformation mechanisms affecting quartz at different metamorphic grades.

\section{Lower Grades}

In the lower-grade samples the effects of dissolution-precipitation creep are dominant and explain the progressive modifications of quartz shape. In the Lindis Pass transect, the increased aspect ratios parallel to lineation, and the blade shapes, were developed through a reduction in thickness and volume of grains, whilst the absolute lengths of grains were generally maintained. Such characteristics indicate diffusive mass transfer as a deformation mechanism, and silica must have been removed from the system or transferred into veins. In the Lake Hawea transect, the increased aspect ratios parallel to lineation, and the blade shapes, were developed through the preferred growth of survivor grains, and these grains increased both in thickness and length, which is not typical of the effects of dissolution-precipitation creep. The growth of the survivor grains must have been accompanied by the complete removal by dissolution of small unstable grains.

\section{Grain shapes: a proxy for strain and a function of strain partitioning?}

In both transects the effects of dissolution-precipitation creep were to produce (by solution and/or growth) blade-shaped grains that mirror the overall rock structure and strain. Thus the longest quartz grain-axes are parallel to the extension direction, and the shortest grain-axes are parallel to the shortening direction. In both transects, dissolution-precipitation creep modified quartz grain shapes so that they eventually attained axial ratios of 1:2:4, comparable to the axial ratios of 1.9:4.75:9 recorded by a deformed conglomerate in the Lake Hawea transect (Norris \& Bishop, 1990). The 
accompanying white micas have axial ratios of 1:7:13 through similar processes of selective grain growth and removal during progressive strain (Stallard \& Shelley, in press). The general structure of the very low grade rocks, with mica-rich solution seams anastomosing around eye-shaped areas dominated by rigid quartz clasts (Figs. $7 \& 8$ ), indicates strain partitioning with higher strains in mica-rich domains. Given the axial ratios noted above, as a first approximation it would seem that the quartz and mica grain shapes are a proxy for these relative strains: thus, the relatively high aspect ratio of mica is a function of the higher proportion of strain partitioned into mica-rich domains, and the relatively low aspect ratio of quartz is a function of the lower proportion of strain in the eye-shaped quartz domains. In combination, the sum of the strains approximated by the mica and quartz grain shapes may be a proxy for the overall rock strain.

The discovery that dissolution-precipitation creep in the Lake Hawea transect increased both thickness and length of survivor grains, at the expense of non-survivor grains, was quite unexpected. These effects are in sharp contrast to those in the Lindis Pass transect where the classic type of dissolution-precipitation creep, with general grain thinning, took place. Nevertheless, the Lake Hawea quartz developments mirror the way in which white micas developed progressively in both transects (Stallard \& Shelley, in press). In the case of white mica, competitive growth occurred in a context where some micas would have existed in unstable orientations susceptible to deformation and preferential removal. In the case of the Lake Hawea quartz it is more difficult to understand the underlying mechanism for selective removal of some grains and the growth of survivor grains in all directions. The effects may possibly be rationalised in terms of increasing grain stability by the sheer increase in grain-size and the removal of smaller grains that had relatively high ratios of surface area to volume.

\section{Higher Grades}

In the higher-grade samples, recrystallisation and plastic deformation quickly took over from dissolution-precipitation creep as the dominant process in modifying quartz grain shapes and orientations. This is a response to the replacement of the discrete, elongate, modified detrital quartz grains within lower grade samples by aggregates of quartz grains within metamorphic layers at higher grades. The quartz within the aggregates underwent dynamic recrystallisation to grains with lower aspect ratios and reduced SPO. The increased contribution of plastic deformation is evident from EBSD data (Figs. 9-11). Internal strain is greater in quartz grains from higher-grade samples (Figs. $9 \& 10$ ) and the pattern of lattice misorientations in at least ten analysed grains from highgrade samples (LP22 and LH11) is consistent with deformation by basal prism slip (Fig. 10; see fig. 4 of Lloyd \& Freeman, 1991 and Lloyd \& Freeman, 1994 for patterns of crystallographic dispersion resulting from different slip systems). Quartz c-axes patterns are largely random until the highestgrade samples (Fig. 11), again indicating a transition from dissolution-precipitation creep to dynamic recrystallisation as the dominant deformation mechanisms in higher-grade samples. Whilst the segregation of quartz into layers allows dynamic recrystallisation to dominate, dissolutionprecipitation creep continues to operate, but the effects of dissolution (pressure solution) are restricted to the margins of quartz-rich layers and aggregates (Fig, 12a) and scarce relict detrital grains located within micaceous layers.

\section{The orienting mechanisms of quartz during schistosity development}

In this section, we use the SPO data to provide constraints on the mechanism and timing of SPO development in the Otago Schist. The mechanisms by which minerals develop shape preferred orientations are crucial in terms of understanding foliation development, and the mechanisms for 
developing both shape and lattice preferred orientations are important for understanding strain mechanisms (Nicolas \& Poirier, 1976; Wenk, 1985). Shelley (1989) noted that there are three categories of orienting mechanisms: mechanical rotation of inequidimensional grains, orientation by various competitive anisotropic growth and/or solution processes, and plastic deformation. These are abbreviated as M, G, and P-type mechanisms respectively.

Sedimentary compaction and diagenesis contributed little to forming an SPO within the analysed samples. This is evident from a comparison of quartz SPO from a non-foliated sample composed entirely of detrital grains (24/11-1) with samples 24/11-4 and LH1, also sub-greenschist facies, but representing the least deformed foliated equivalents of 24/11-1 (Figs. 4 \& 5). Sample 24/11-1 has only a weak SPO and quartz grains have small aspect ratios. In contrast, samples 24/114 and LH1 record higher aspect ratios and strong quartz SPO.

We have shown in earlier sections that quartz shape preferred orientations developed whilst dissolution-precipitation creep processes were operating in response to progressive strain, and that the shapes may be proxy for the magnitude and orientation of strain. This is an example of quartz developing its SPO by a G-type mechanism. However, in the very low-grade Otago Schists, quartz grains are relatively rigid inequidimensional objects in a severely strained rock-mass, and it is necessary to ask what part mechanical rotation of the quartz grains played in the orienting process. We discuss this in terms of four scenarios portrayed in Fig. 13, which consider various combinations of dissolution-precipitation creep, mechanical rotation, and simple shear as orienting mechanisms of the quartz grains.

Several studies have documented non-coaxial strain, akin to simple shear, within the Otago Schist (Mortimer, 1993b; Cooper, 1995), and the $\sigma$-shaped quartz grains described above give further evidence of this, although microstructures more typical of coaxial strain are observed in other samples (e.g. Fig. 8). The $\sigma$-shaped structures described here, and the structures described by Mortimer (1993b) and Cooper (1995), all suggest that the linear aspect of the foliation is parallel to the direction of tectonic movement. We conclude, therefore, that the combination of $\sigma$-shaped structures (Fig. 7), quartz grains with long axes at a high angle to foliation (Fig. 8), and the lack of $\delta$-shaped structures, provide support for the scenarios portrayed in Fig. 13a,c with scenario (a) representing a lesser degree of non-coaxiality in strain. It is difficult to rule out scenario (b) altogether, but there is no evidence for it, and the lack of $\delta$-shaped structures argues against scenario (d).

We conclude, therefore, that mechanical rotation of rigid inequidimensional quartz clasts was not a major factor in developing the quartz SPO in the very low grade Otago Schists. We note, too, that grain shape modifications by dissolution-precipitation creep, such as that shown in scenario (a), have the effect of reducing the likelihood of mechanical grain rotations. It is likely, therefore, that any grain rotation would have occurred early in the process.

Plastic deformation is not an important process in the development of quartz SPO or LPO in the lower grade rocks. This is evidenced by the lack of internal strain features in the quartz grains or a lattice preferred orientation (Figs. 9-11). This is not surprising given the low grade conditions, and it is already well established that discrete quartz grains set in a more ductile matrix of sheet silicates do not usually undergo plastic deformation, the strain being taken up in the matrix material (Starkey \& Cutforth, 1978; Walnuik \& Morris, 1985), or by processes such as dissolution-precipitation creep affecting the quartz.

In higher grade samples, dissolution-precipitation creep was superseded by dynamic recrystallisation as the most important factor in orienting the quartz. This is consequential to the aggregation of quartz grains during the production of metamorphic segregation layering, and the 
increasing scarcity of discrete grains. The main feature of the quartz preferred orientation is now an LPO, the result of plastic deformation, as described above. An SPO is still present, but it is weak, and it probably results from the pinning of quartz grain boundaries during recrystallisation of the micas scattered through the quartz-rich layers (Fig. 12b; cf Shelley, 1993, fig. 2.22).

\section{Fold events as key stages in foliation development}

\section{$F_{1}$ folding and the onset of dissolution-precipitation creep}

Within the Otago Schist, the transition from non-foliated sedimentary rocks to foliated low-grade schists occurred early in the deformation history, at sub-greenschist facies conditions, coinciding with the development of $F_{1}$ folds. $F_{1}$ related strain was a key factor in initiating foliation through shape modification of detrital quartz grains by dissolution-precipitation creep and oriented growth of metamorphic mica following strain-induced breakdown of detrital grains (Fig. 14; Stallard \& Shelley, in press). The blade-shapes of the quartz and mica grains define the planar aspect of the foliation, and the long axes of the blades define the linear aspect of the foliation, parallel to fold axes of tight to isoclinal $\mathrm{F}_{1}$ folds of bedding. It is the combination of quartz and mica SPO that defines the $S_{1}$ foliation, sub-parallel to bedding and parallel to the axial planes of $F_{1}$ folds. Dissolutionprecipitation creep in these low-grade rocks was active at sub-greenschist facies conditions, so we consider that strain rather than temperature was the dominant control on the early development of quartz SPO. Conditions of high strain are indicated by the axial ratios of deformed conglomerates, which indicate up to $50 \%$ flattening of the rock mass (Norris \& Bishop, 1990). The early-formed SPO persists in character with increasing grade, and is progressively intensified by an increase in aspect ratio and alignment of both quartz (Figs. 5c,g \& 14) and muscovite (Stallard \& Shelley, in press, fig. 6c,g).

\section{$F_{2}$ folding and the development of segregation layering}

Higher grade samples from both the Lindis Pass and Lake Hawea transects (but still within the chlorite zone, greenschist facies) record the development of a crenulation cleavage during $\mathrm{F}_{2}$ folding. $\mathrm{F}_{2}$ folding is accompanied by progressive segregation into quartz and mica-rich layers, and segregation is accentuated by the reorientation of pre-existing veins parallel to schistosity. Many veins were boudinaged or otherwise broken during crenulation, and these contribute to the segregation in the form of lenses and truncated layers of vein quartz.

Segregation of quartz from mica marks an important change in the degree to which quartz SPO contributes to the definition of schistosity. Prior to the development of segregation layering, most quartz grains occurred as relic detrital grains dispersed throughout individual beds within a matrix of white mica and other sheet silicates (e.g. Fig. 2b), and these quartz grains display increased aspect ratios as a consequence of dissolution-precipitation creep. During $\mathrm{F}_{2}$ crenulation folding, quartz was preferentially removed from crenulation limbs by pressure solution, and the resulting quartz-rich hinge zones and mica-rich limbs are the foundation for segregation of the rock mass. The texture in the quartz-rich domains is a recrystallised mosaic with a high percentage of quartz-quartz contacts at grain boundaries (Fig. 14), markedly different from the previously discrete detrital grains. Dissolution of quartz is now restricted to the margins of the quartz-rich layers. Within the layers, quartz grain shapes are typical of mosaics that result from dynamic recrystallisation, and aspect ratios are reduced (Figs. 4a,b \& 5h, see sample LP22). The residual quartz SPO in the quartz-rich layers may partly be due to the presence of large oriented micas, 
which effectively pinned quartz grain boundaries during recrystallisation (Fig. 12b; cf Shelley, 1993, fig. 2.22).

Although the contribution of quartz to the definition of foliation is markedly reduced during $\mathrm{F}_{2}$ folding and segregation of the rock mass, the sheet silicate SPO remains largely unaffected (Stallard \& Shelley, in press). Therefore, progressively with increasing grade, the rock structure becomes more and more defined by the shape and orientation of segregation layers, plus a foliation, which, in the strict sense used in this paper, is now defined dominantly by sheet-silicates.

\section{CONCLUSIONS}

1. Quartz SPO, in combination with mica SPO, plays an important role in defining the foliation in the lowest grade (sub-greenschist facies) metamorphic rocks of the Otago Schist.

2. The key mechanism for developing the quartz SPO was dissolution-precipitation creep so that the aspect ratios of discrete detrital quartz grains increased in sections parallel to lineation, and grains became blade-shaped. The preferred orientation of the blade-shaped quartz grains developed early in the deformation history at the lowest metamorphic grades.

3. The blade shaped quartz grains eventually attained axial ratios of $1: 2: 4$, with the planes of the blades defining the planar aspect of the foliation, and blade lengths the linear aspect of the foliation (lineation).

4. The principal mechanism for orienting the blade shaped quartz is the grain-shaping process of dissolution-precipitation creep, which accommodated the extension and shortening of the rock by varying degrees of grain solution and/or growth.

5. At higher grades within the chlorite zone of the greenschist facies, the development of segregation layering and the aggregation of quartz into layers was accompanied by a change in the quartz deformation mechanism from dissolution-precipitation creep to dynamic recrystallisation. This event coincides with crenulation of the rock mass.

6. Dynamic recrystallisation caused a reduction in aspect ratios of quartz grains and a consequential reduction in the contribution of quartz to the foliation. A weak quartz SPO still exists, partly due to the pinning effects of dispersed oriented micas on quartz grain boundary migration within the quartz-rich layers. Dissolution of quartz in the higher grade schists was almost entirely restricted to the margins of the quartz-rich layers rather than individual grains.

7. Foliation in the higher grade rocks is defined dominantly by the SPO of mica while the overall rock structure is characterised by a marked quartz and mica segregation layering.

\section{ACKNOWLEDGEMENTS}

This project was funded by the Foundation for Research, Science and Technology, New Zealand. We thank Rob Spiers, University of Canterbury, for the production of thin sections, and Craig Buchan, Curtin University of Technology, for assistance with EBSD analyses.

\section{REFERENCES}

Bishop, D. G., 1972. Progressive metamorphism from prehnite-pumpellyite to greenschist facies in the Danseys Pass area, Otago, New Zealand. Bulletin of the Geological Society of America, 83, 3177-3198. 
Bestmann, M., Prior, D. J. \& Veltkamp, K. T. A., 2004. Development of single-crystal -shaped quartz porphyroclasts by dissolution-precipitation creep in a calcite marble shear zone. Journal of Structural Geology, 26, 869-883.

Cooper, A. F., 1980. Retrograde alteration of chromian kyanite in metachert and amphibolite whiteschist from the Southern Alps, New Zealand, with implications for uplift on the Alpine Fault. Contributions to Mineralogy and Petrology, 75, 153-164.

Cooper, E. K., 1995. Petrofabric studies across the Caples/Torlesse terrane boundary, Otago Schist, New Zealand. Unpublished MSc Thesis, University of Canterbury, Christchurch, New Zealand, 292 pages.

Forster, M.A. \& Lister, G.S., 2003. Cretaceous metamorphic core complexes in the Otago Schist, New Zealand. Australian Journal of Earth Sciences, 50, 181-198.

Grapes, R. H. \& Watanabe, T., 1994. Mineral composition variation in Alpine Schist, Southern Alps, New Zealand: implications for recrystallisation and exhumation. The Island Arc, $\mathbf{3}$, 163-181.

Gray, D.R. \& Foster, D.A., 2004. 40Ar/39Ar thermochronologic constraints on deformation, metamorphism and cooling/exhumation of a Mesozoic accretionary wedge, Otago Schist, New Zealand. Tectonophysics, 385, 181-210.

Hutton, C. O. \& Turner, F. J., 1936. Metamorphic zones in north-west Otago. Transactions of the Royal Society of New Zealand, 65, 405-406.

Ildefonse, B., Lardeaux, J. M. \& Caron, J. M., 1990. The behavior of shape preferred orientations in metamorphic rocks; amphiboles and jadeites from the Monte Mucrone area (Sesia-Lanzo zone, Italian Western Alps). Journal of Structural Geology, 12, 1005-1011.

Little, T. A., Mortimer, N. \& McWilliams, M., 1999. An episodic Cretaceous cooling model for the Otago-Marlborough Schist, New Zealand, based on ${ }^{40} \mathrm{Ar} /{ }^{39} \mathrm{Ar}$ white mica ages. New Zealand Journal of Geology and Geophysics, 42, 305-325.

Lloyd, G. E. \& Freeman, B., 1994. Dynamic recrystallisation of quartz under greenschist conditions. Journal of Structural Geology, 16, 867-881.

Lloyd, G. E. \& Freeman, B., 1991. SEM electron channelling analysis of dynamic recrystallisation in a quartz grain . Journal of Structural Geology, 13, 945-953.

Miyake, A., 1993. Rotation of biotite porphyroblasts in pelitic schist from the Nukata area, central Japan. Journal of Structural Geology, 15, 1303-1313. 
Mortimer, N., 1993a. Geology of the Otago Schist and adjacent rocks. Scale 1:500 000. Institute of Geological and Nuclear Sciences geological map 7. Institute of Geological and Nuclear Sciences Ltd, Lower Hutt, New Zealand.

Mortimer, N., 1993b. Jurassic tectonic history of the Otago Schist, New Zealand. Tectonics, 12, 237-244.

Mortimer, N. \& Roser, B. P., 1992. Geochemical evidence for the position of the Caples-Torlesse boundary in the Otago Schist, New Zealand. Journal of the Geological Society of London, 149, 967-977.

Mulchrone, K. F., 2002. A statistic for estimating strain with confidence intervals from deformed line distributions with an application to schists and gneisses of the Western Gneiss Region, west central Norway. Journal of Structural Geology, 24, 545-556.

Nicolas, A. \& Poirier, J. P., 1976. Crystalline plasticity and solid state flow in metamorphic rocks. Wiley, London.

Nishimura, Y., Coombs, D. S., Landis, C.A. \& Itaya, T., 2000. Continuous metamorphic gradient documented by graphitization and K-Ar age, southeast Otago, New Zealand. American Mineralogist, 85, 1625-1636.

Norris, R. J. \& Bishop, D. G., 1990. Deformed conglomerates and textural zones in the Otago Schists, South Island, New Zealand. Tectonophysics, 174, 331-349.

Passchier, C. W. \& Simpson, C. 1986. Porphyroclast systems as kinematic indicators. Journal of Structural Geology, 8, 831-843.

Rivers, T. \& Fyson, W. K., 1977. Shape, size and orientation of muscovite crystals in a schist of variable metamorphic grade. Canadian Journal of Earth Science, 14, 185-195.

Scrope, G. P., 1825. Considerations on volcanos: the probable causes of their phenomena, the laws which determine their march, the disposition of their products, and their connexion with the present state and past history of the globe, leading to the establishment of a new theory of the earth. Phillips, London.

Shelley, D., 1979. Plagioclase preferred orientation, Foreshore Group Metasediments, Bluff, New Zealand. Tectonophysics, 58, 279-290.

Shelley, D., 1989. P, M and G tectonites: a classification based on origin of mineral preferred orientations. Journal of Structural Geology, 11, 1029-1037.

Shelley, D., 1993. Igneous and Metamorphic Rocks under the Microscope. Chapman and Hall, London.

Shelley, D., 1995. Asymmetric shape preferred orientations as shear-sense indicators. Journal of Structural Geology, 17, 509-517.

Stallard, A. R. \& Shelley, D. 1995. Quartz c-axes parallel to stretching directions in very low grade metamorphic rocks. Tectonophysics, 249, 31-40.

Stallard, A. R. \& Shelley, D., in press. The initiation and development of metamorphic foliation in the Otago Schist, Part 1: Competitive oriented growth of white mica. Journal of Metamorphic Geology, in press. 
Starkey, J. \& Cutforth, C. 1978. A demonstration of the interdependence of the degree of quartz preferred orientation and the quartz content of deformed rocks. Canadian Journal of earth Science, 15, 841-847.

Turnbull, I. M., Mortimer, N. \& Craw, D., 2001. Textural zones in the Haast Schist- a reappraisal. New Zealand Journal of geology and Geophysics, 44, 171-183.

Turner, F. J., 1935. Metamorphism of the Te Anau Series in the region north-west of Lake Wakatipu. Transactions of the Royal Society of New Zealand, 65, 329-349.

Walniuk, D. M. \& Morris, A. P., 1985. Quartz deformation mechanisms in metasediments from Prins Karls Forland, Svalbard. Tectonophysics, 115, 87-100.

Wenk, H. R., 1985. Preferred orientation in deformed metals and rocks: an introduction to modern texture analysis. Academic Press, Orlando.

Williams, P. F., 1972. Development of metamorphic layering and cleavage in low grade metamorphic rocks at Bermagui, Australia. American Journal of Science, 272, 1-47.

Yardley, B. W. D., 1982. The early metamorphic history of the Haast Schists and related rocks of New Zealand. Contributions to Mineralogy and Petrology, 81, 317-327.

Yassaghi, A., James, P. R. \& Flottmann, T., 2000. Geometric and kinematic evolution of asymmetric ductile shear zones in thrust sheets, southern Adelaide Fold-Thrust Belt, South Australia. Journal of Structural Geology, 22, 889-912.

\section{Figure Captions}

Fig. 1. (a) Location map of Otago Schist, South Island, New Zealand. (b) Simplified regional geology of the Otago Schist and location of transect areas (boxes at upper centre- these are enlarged in (c) and (d)). The schist is subdivided into textural zones (I-IV) based on white mica grain size, degree of foliation development, and degree of segregation layering development. See Turnbull et al. (2001) for full discussion and definition of textural zones. Map is modified from Turnbull et al. (2001, fig. 7). (c,d) Simplified geology and sample localities of the Lake Hawea (c) and Lindis Pass (d) transects.

Fig. 2. Photomicrographs of representative quartz grains in samples of increasing metamorphic grade and textural development. Sample numbers are given in top left of figures, and sample locations are given in Fig. 1. (a) TZ1 sandstone containing detrital quartz (b) Detrital quartz grains deformed by dissolution-precipitation creep. (c) Elongate single grain of quartz. Note long thin terminations of the grain parallel to schistosity. (d) Recrystallised and segregated quartz mosaic from the highest-grade sample analysed (LP22). All photographs taken under cross-polarised light. 
Fig. 3. Structural data from the Lake Hawea transect. (a) Composite bedding $/ S_{1}, S_{2}$ and lineation data. (b) Fold orientation data. Both stereoplots are equal area lower hemisphere projections.

Fig. 4. Quartz shape data from the Lindis Pass and Lake Hawea transects. All data are mean values from an average 76 measurements per section. (a,b) Aspect ratio data. (c,d) Grain shape data.

Fig. 5. Quartz shape orientation data (histograms) and 3D shape reconstructions for representative samples from the Lake Hawea transect (a-d in order of increasing metamorphic grade) and Lindis Pass transect (e-h in order of increasing metamorphic grade). Location of each sample can be determined from Fig. 1. Photomicrographs are taken under cross polarized light except for (e), which is under plane polarized light. Vertical black lines on plots indicate the orientation of the foliation as estimated visually from thin section. Black diamond-shaped symbols indicate aspect ratio of measured grains. The two reconstructed 3D grains for each sample represent the dimensions of the $25^{\text {th }}$ and $75^{\text {th }}$ percentile grains from the sampled population. The scale of the reconstructed grains is illustrated in (a).

Fig. 6. Example of the contrasting apparent shape and orientation of quartz grains in sections oriented parallel and perpendicular to lineation. ( $\mathrm{a}$ and $\mathrm{b}$ ) Photomicrographs of sections cut parallel and perpendicular to lineation from sample LP11. Photomicrographs are cross polarised light. (c and d) Orientation distribution data for quartz from sample LP11. Black vertical lines on plots indicate the orientation of the foliation as estimated visually from thin section.

Fig. 7. $\sigma$-shaped aggregates of quartz grains from sample LP8. (a) and (b) show the same view in plane- and cross-polarised light respectively. (c) is taken under plane-polarised light and (d) under cross-polarised light.

Fig. 8. Photomicrographs of two elongate detrital quartz grains oriented at a high angles to foliation. While prominent solution seams have developed at the upper and lower margins of the grains, the grains have not undergone syn-deformation rotated into the plane of the foliation. 
Fig. 9. Average intra-grain variation in lattice orientation (measured in degrees) of quartz grains from samples of increasing metamorphic grade. Number of grains analysed in each sample are as follows: 24/11-1 (3 grains), LH1 (14 grains), LH25 (22 grains), LH10 (12 grains), LH20 (8 grains), and LP22 (6 grains).

Fig. 10. Crystal orientation data collected by EBSD for two quartz grains of contrasting internal strain. (a) Colour-coded lattice orientation map of a representative grain from sample LH1. The colour-scale (blue-red) indicates variation in lattice orientation totaling $3^{\circ}$. Step size is $3 \mu \mathrm{m}$. (b-d) Lower hemisphere equal angle projections of quartz lattice orientation data (c, $\mathrm{z}$ and $\mathrm{m}$ orientations) for grain shown in (a). Geometric relationship between $\mathrm{c}, \mathrm{z}$ and $\mathrm{m}$ is shown in inset in (b). Colours correspond directly to position of data point in (a). S and L indicate orientation of schistosity and lineation respectively. (e) Orientations of misorientation axes, plotted in crystal coordinates, These data show the orientation of misorientation axes between adjacent analysis points with misorientations of between 2 and $10^{\circ}$. (f-j) Equivalent data to that shown in (a-e) for analysis of a representative quartz grain from sample LP22. Total variation represented by the colour scale in (f) is $15^{\circ}$, and step size is $1 \mu \mathrm{m}$.

Fig. 11. Quartz c-axis orientations in samples of increasing metamorphic grade. Stereoplots are lower hemisphere, equal area projections. In all plots, schistosity (S) is oriented vertical, with an east-west strike, while the lineation (L) is horizontal with an east-west trend. Note the oblique girdle pattern of c-axes discernable in the pole diagram for sample LP22 (bottom left of figure).

Fig. 12. Photomicrographs of quartz textures in higher-grade samples. (a) Quartzose aggregate affected by dissolution of the aggregate margin, resulting in convex embayments and dark seams of insoluble material at aggregate margin. The aggregate contains numerous largely unstrained quartz grains. (b) Photomicrograph and accompanying line diagram of recrystallised quartz grains abutting muscovite grains with a strong SPO. In line diagram, dark grains are muscovite and white grains quartz.

Fig. 13. Four contrasting scenarios for producing quartz SPO in the analysed samples. Each scenario consists of three sketches that illustrate the progressive development of the SPO for an individual 
grain. (a) An inequidimensional detrital quartz grain responds to a pure shear deformation by undergoing pressure solution on boundaries at a high angle to the shortening direction (gray areas in central figure) and growth on other boundaries (striped pattern in right-hand figure). (b) The grain at first responds to the pure shear mainly by a mechanical rotation, and then responds to the strain by dissolution-precipitation creep induced shape modification. (c) The rock is subject to something similar to simple shear, and the grain rotates passively in response to strain and develops asymmetric growth tails. (d) The quartz grain rotates freely in response to the simple shear as is proposed by many workers for garnets with curved inclusion trails.

Fig. 14. Generalised model of foliation development in the Otago Schist in terms of quartz and muscovite SPO trends. Three stages of foliation development are depicted, separated by two key events in the evolution of quartz and muscovite SPO. Black diamond-shaped symbols on histograms indicate aspect ratios of measured grains, while vertical black lines indicate orientation of foliation as estimated visually from thin section.

Table 1. Summary of structural and metamorphic trends along Lake Hawea and Lindis Pass transects. All data is from present study. Distance of each sample from transect starting point is indicated, in km, immediately below each sample number. 


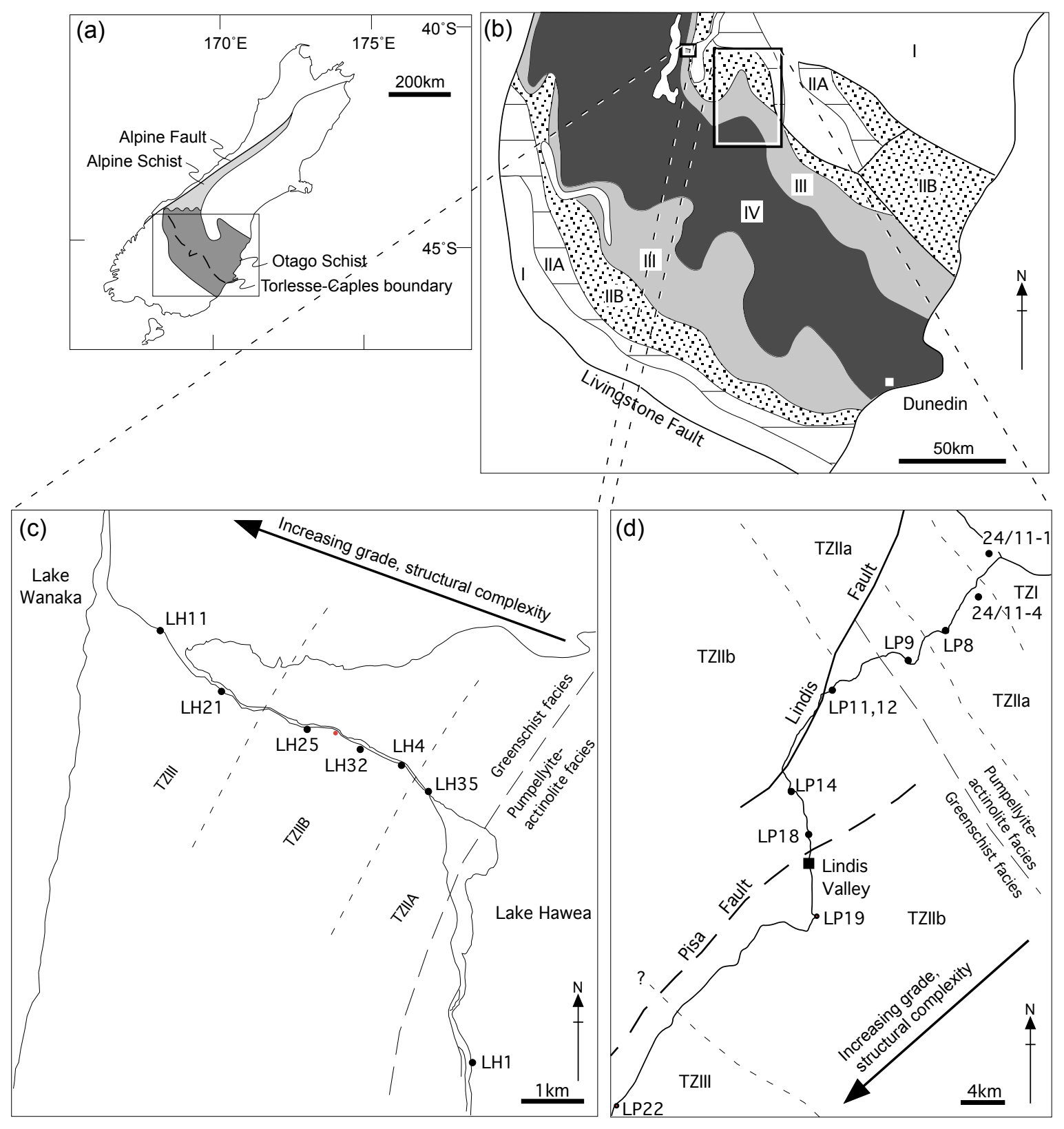

Figure 1 
(a)

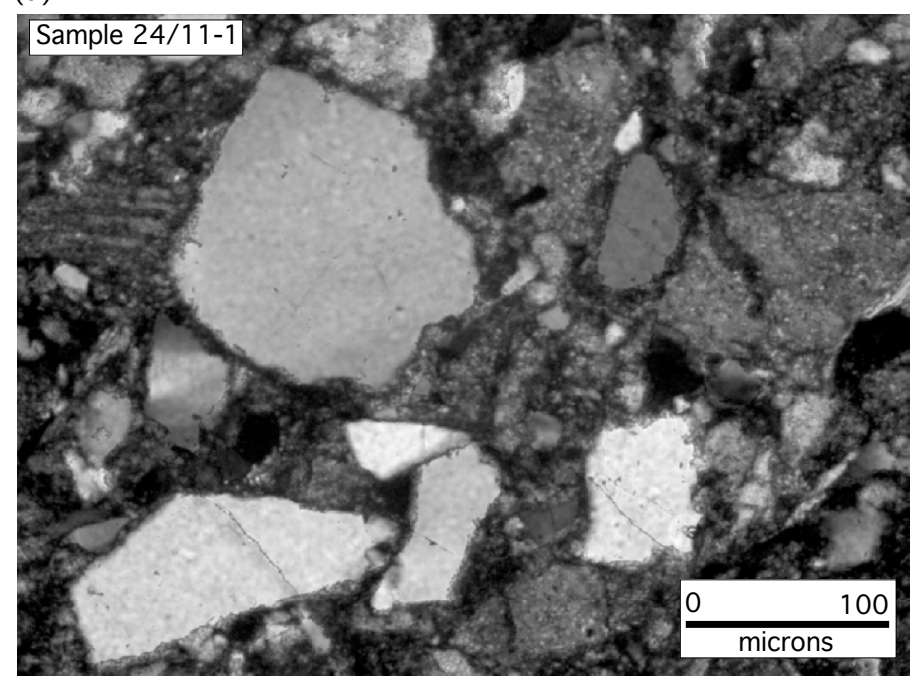

(c)

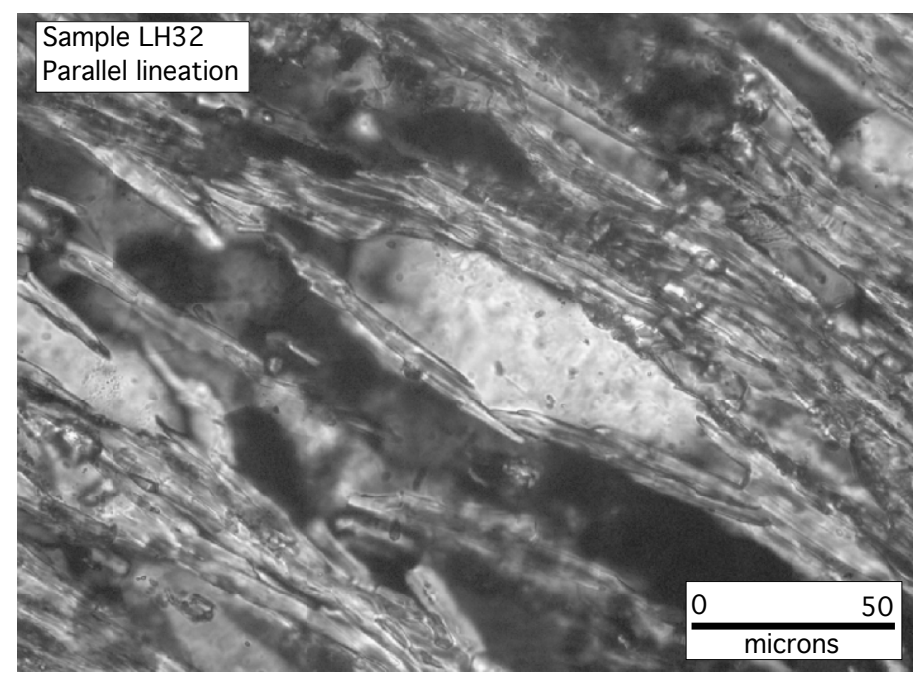

(b)

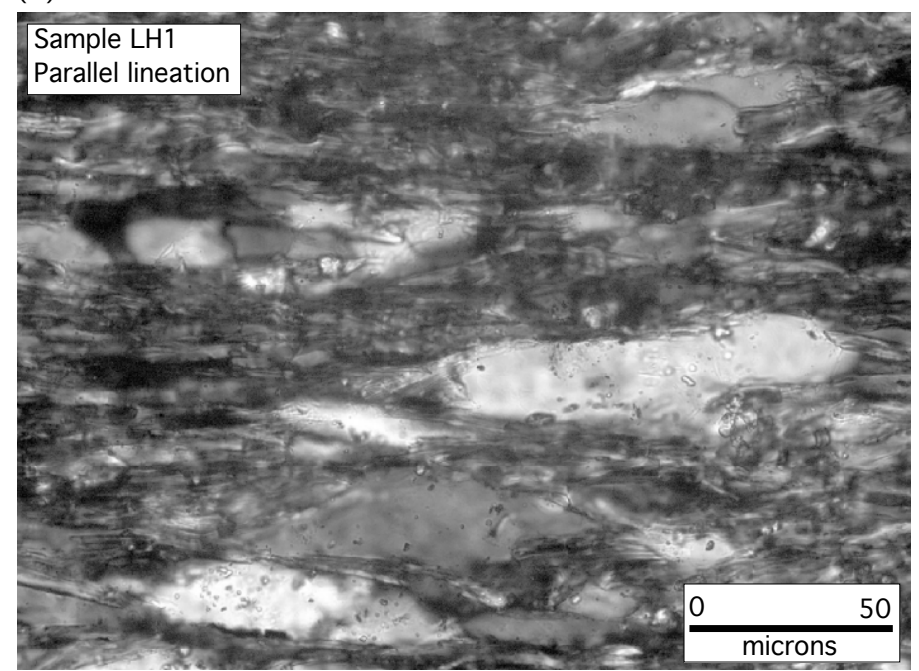

(d)

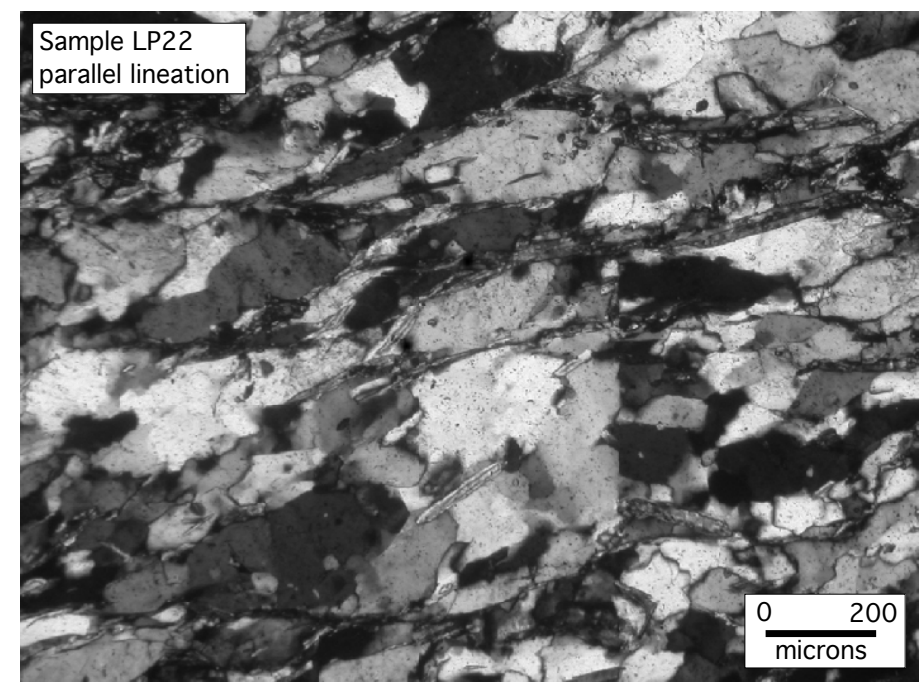

Figure 2 

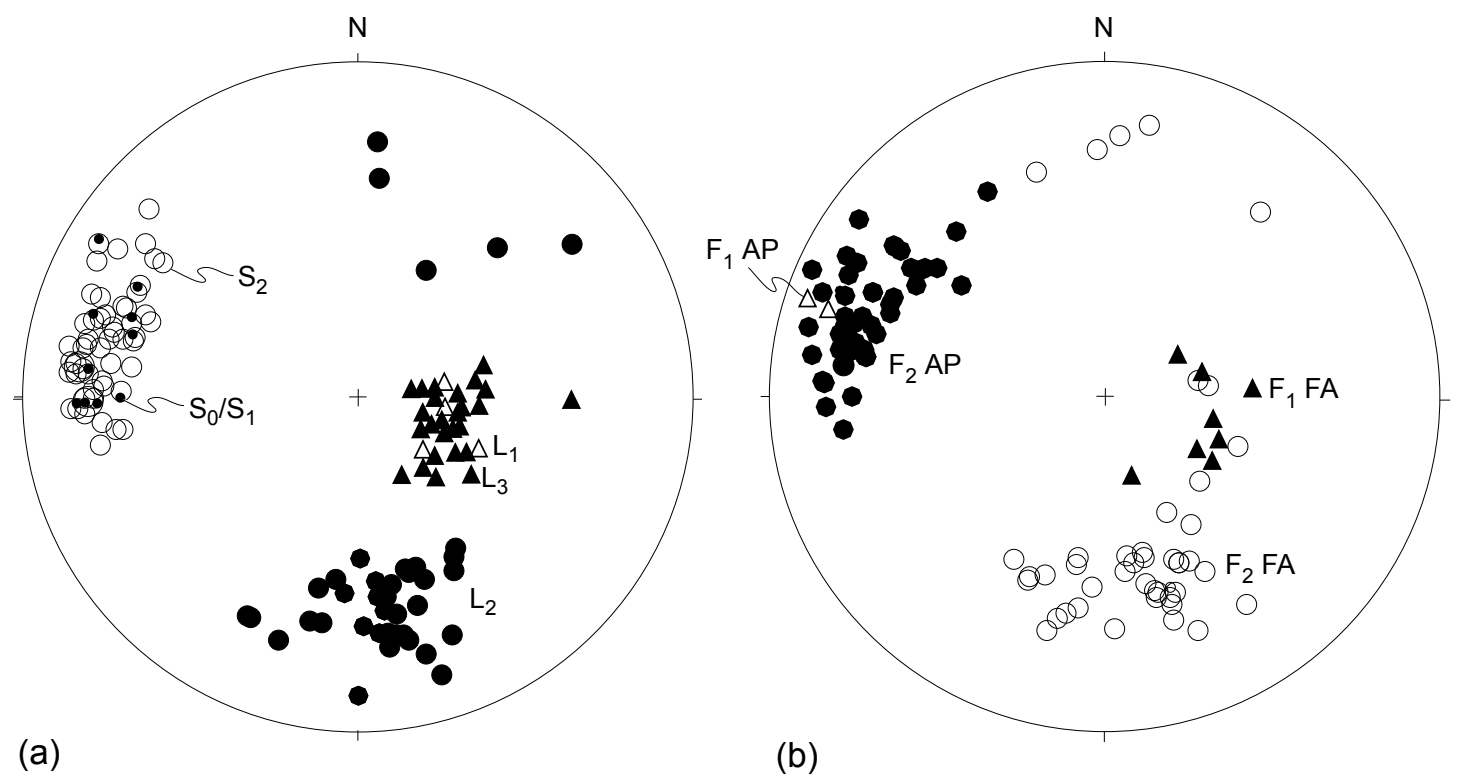

Figure 3 
(a) Lindis Pass Aspect Ratio Data

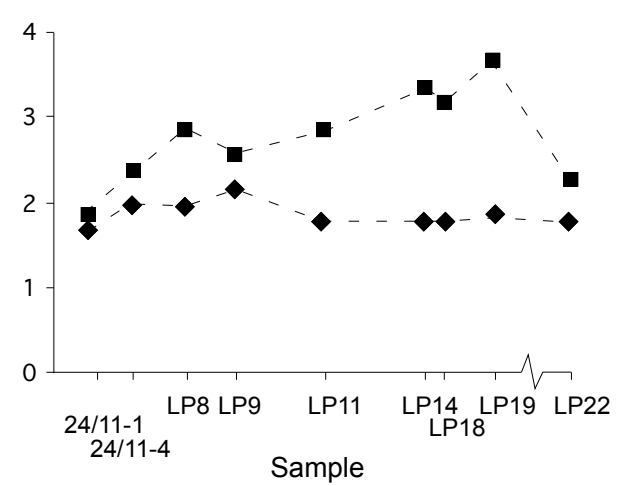

(c)

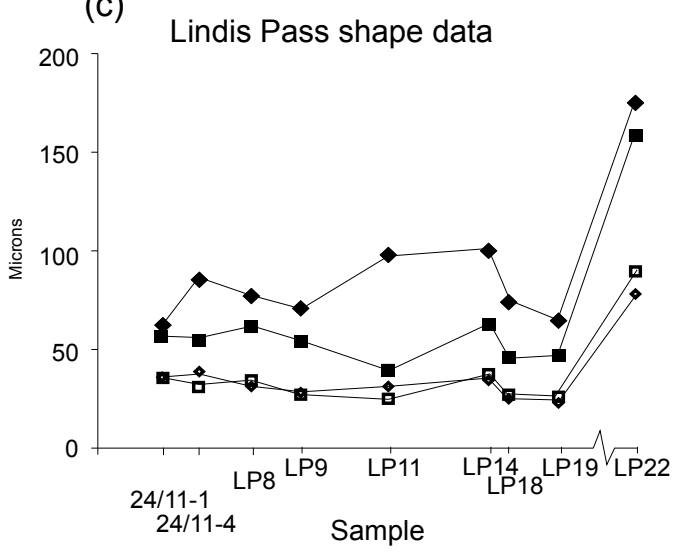

(b) Lake Hawea Aspect Ratio Data

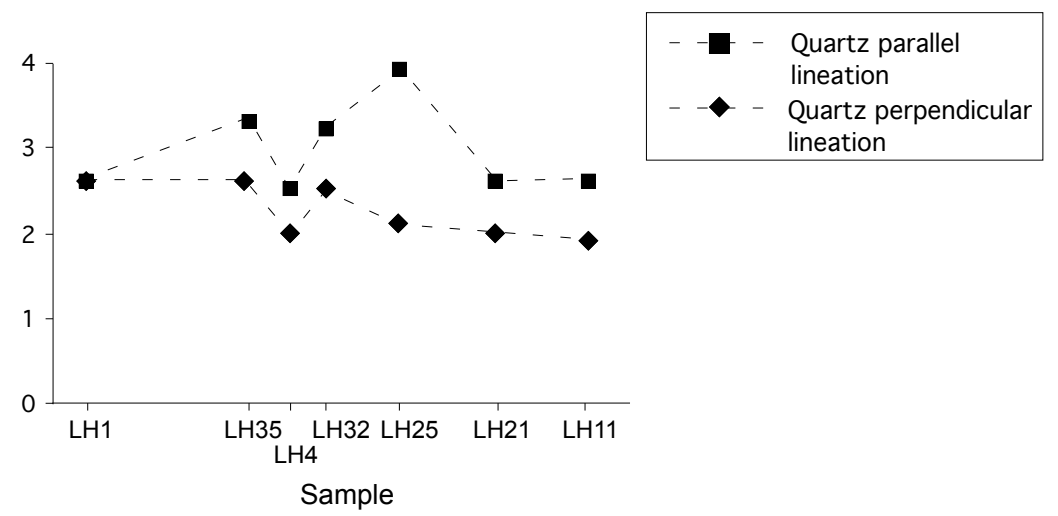

(d)

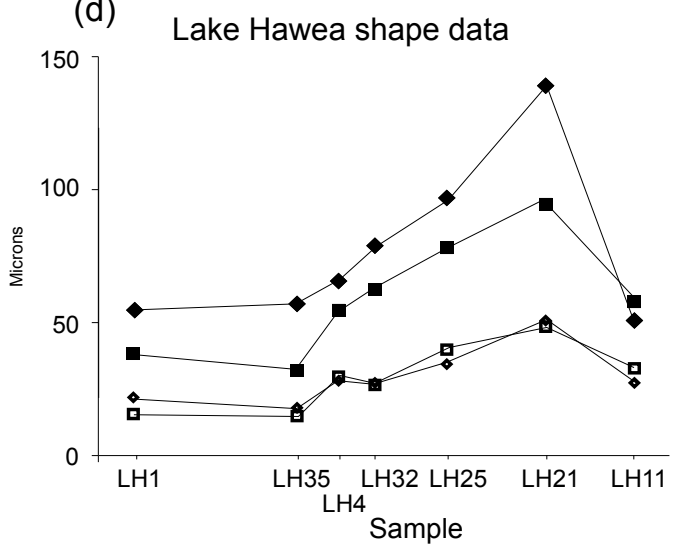

Figure 4 

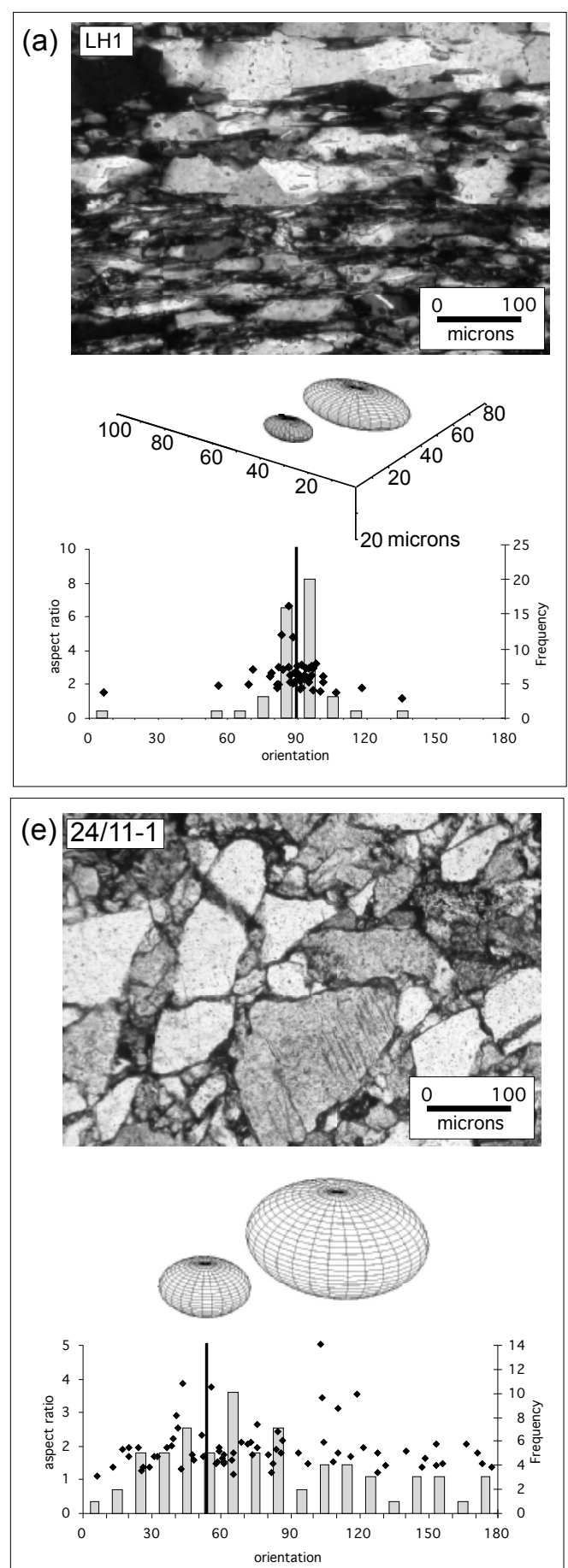
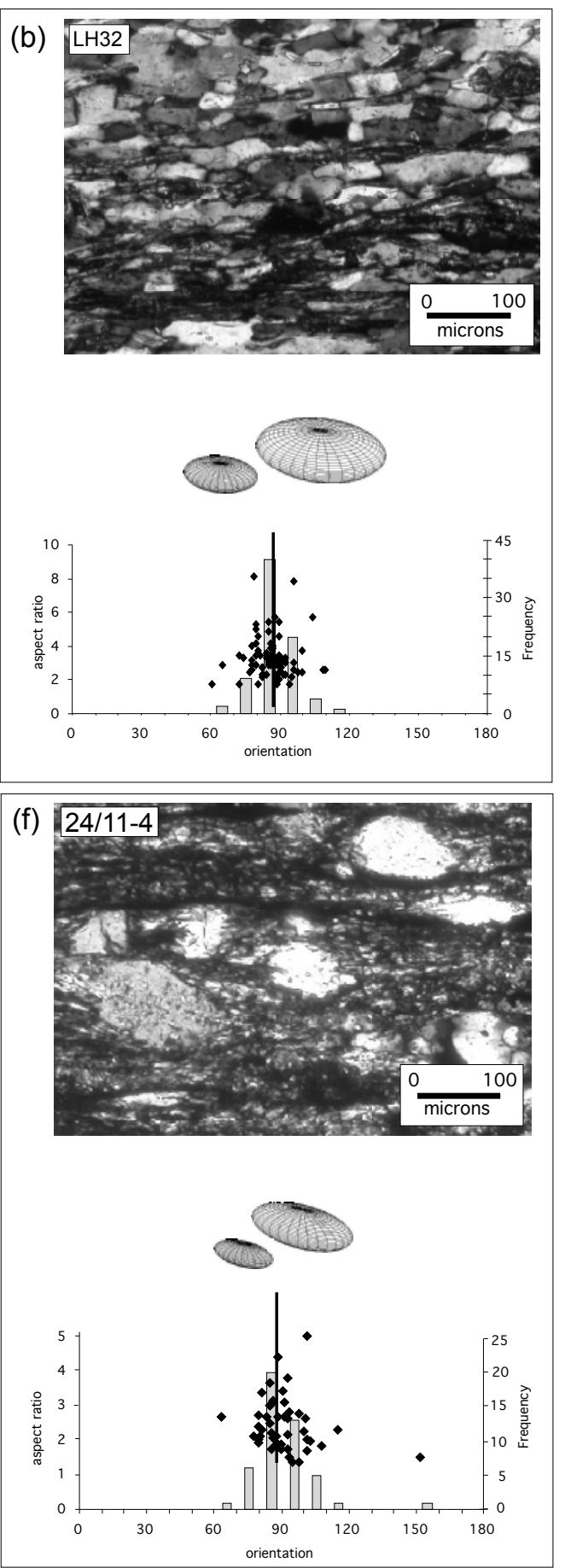
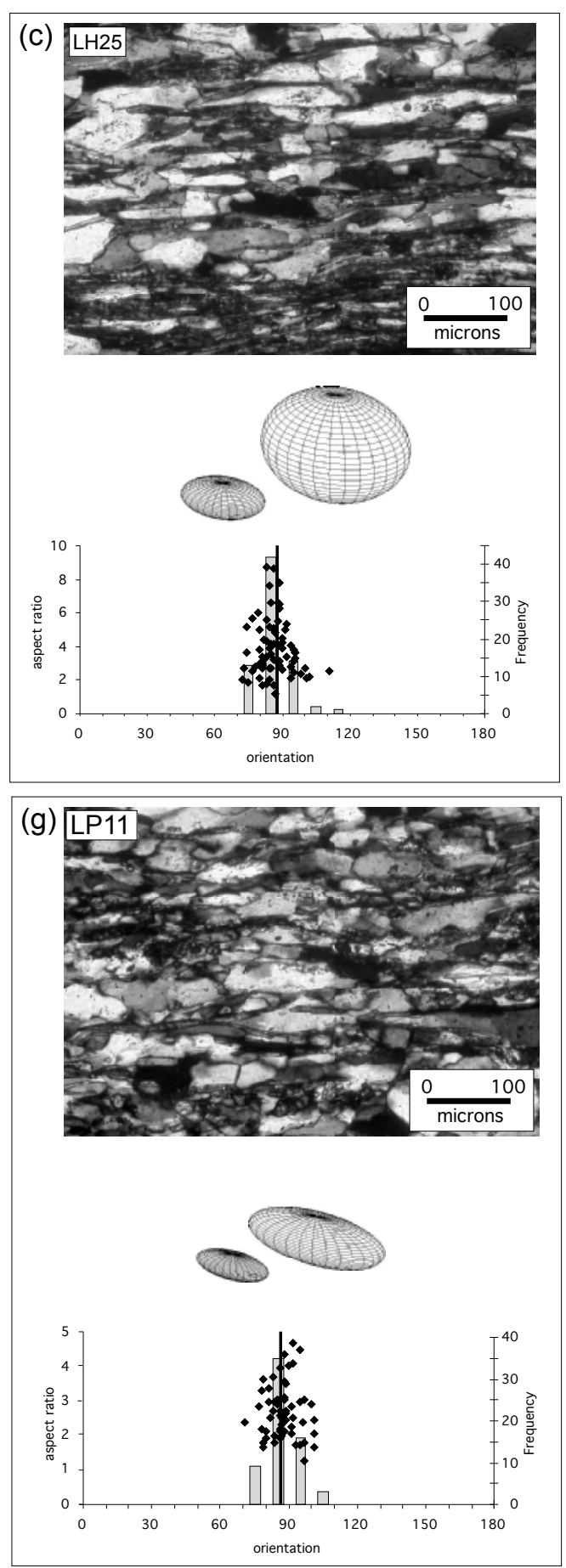
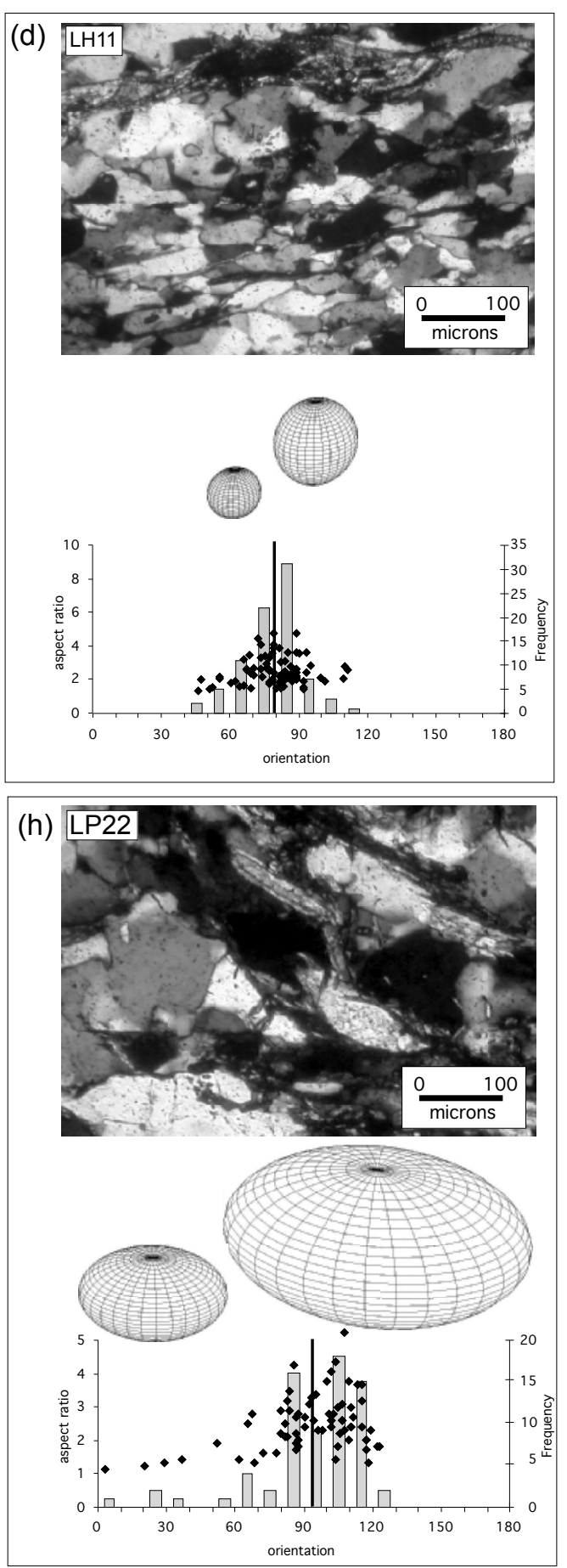
(a)

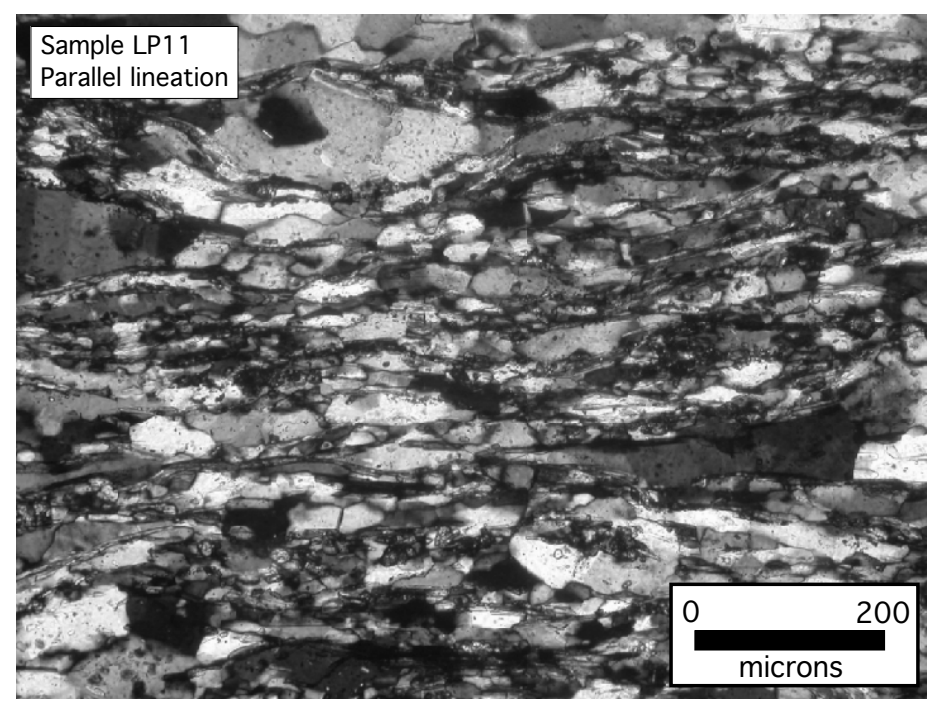

(c)

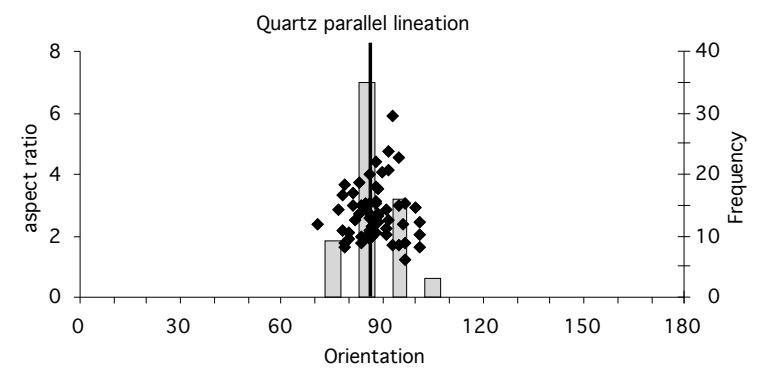

(b)

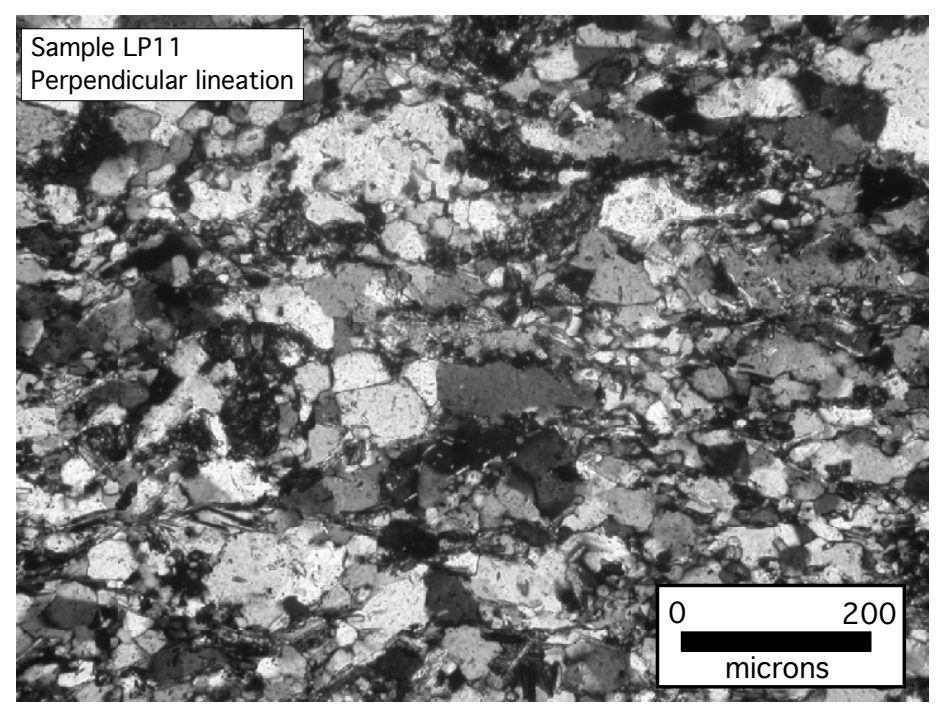

(d)

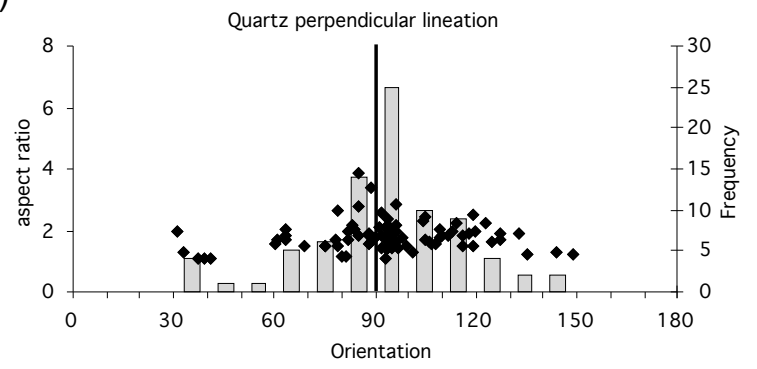

Figure 6 
(a)

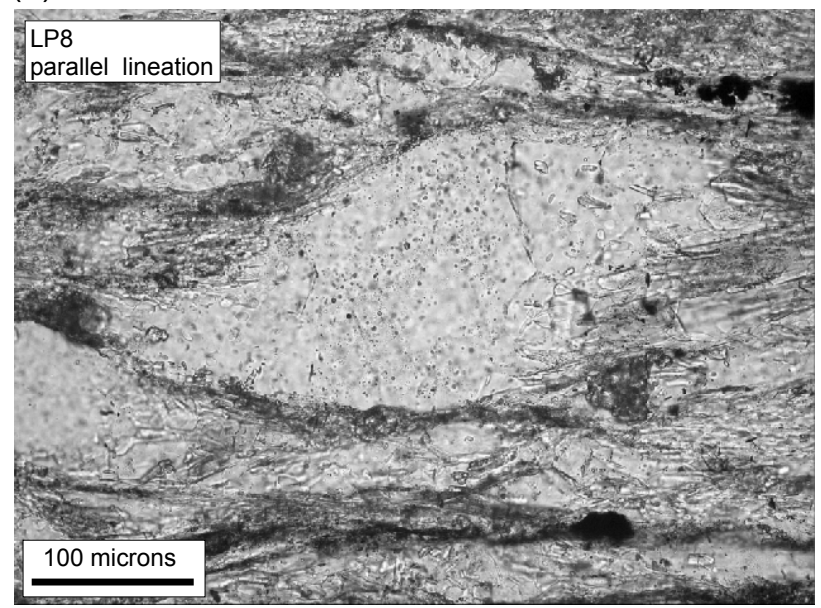

(c)



(b)

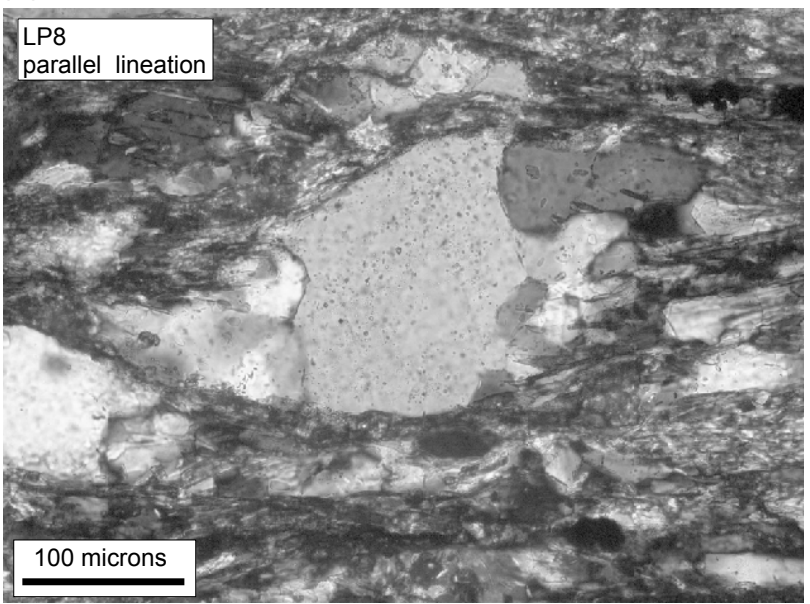

(d)

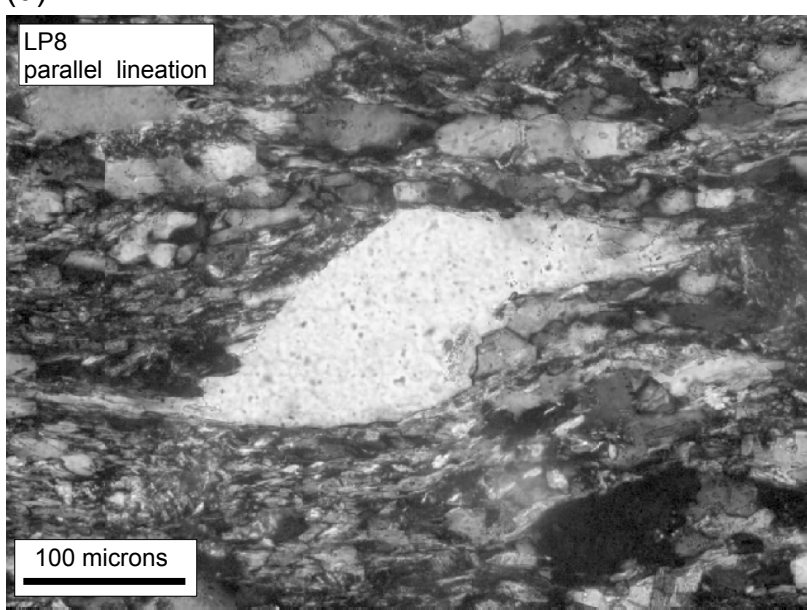

Figure 7 
(a)



(b)

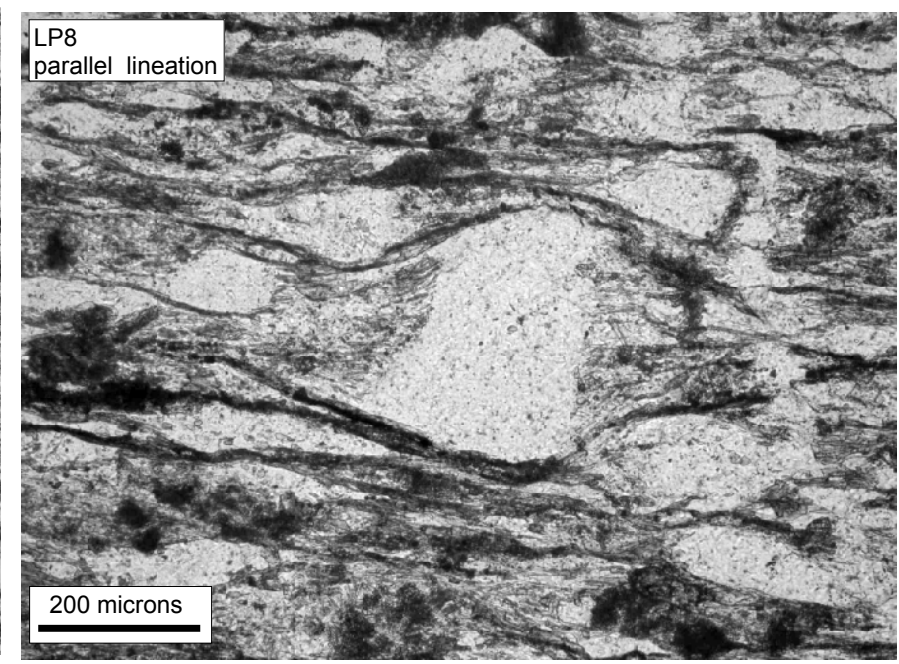

Figure 8 


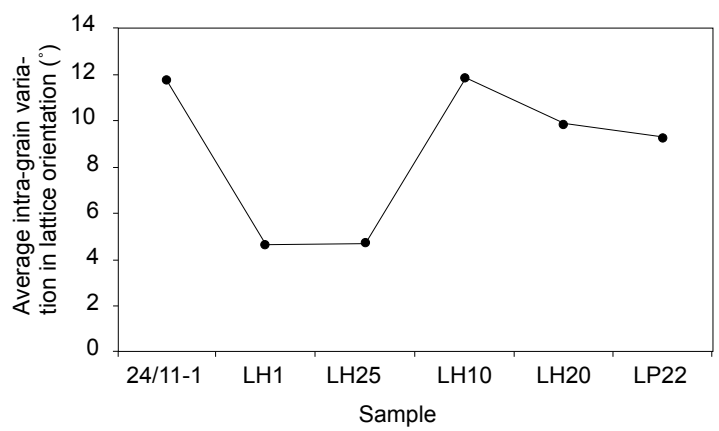

Figure 9 
(a)



(f)

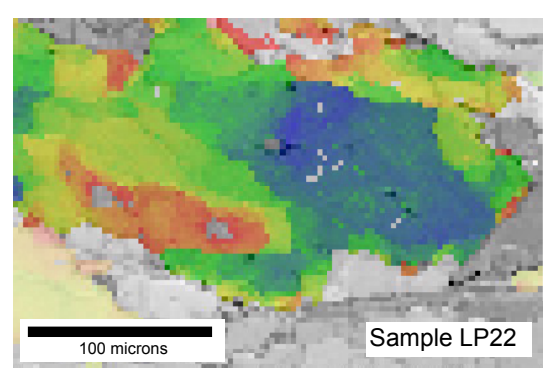

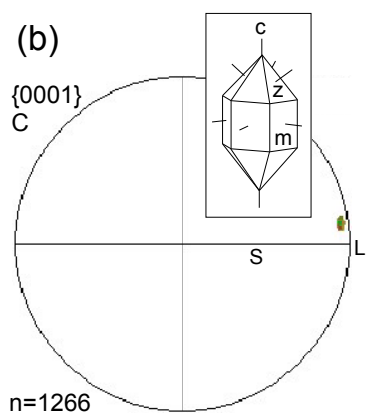

(g)

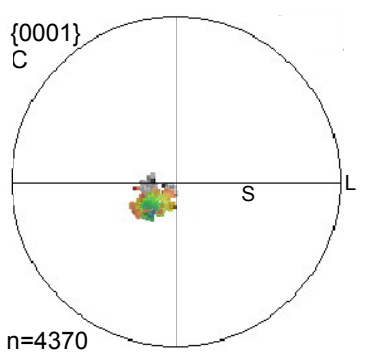

(c)

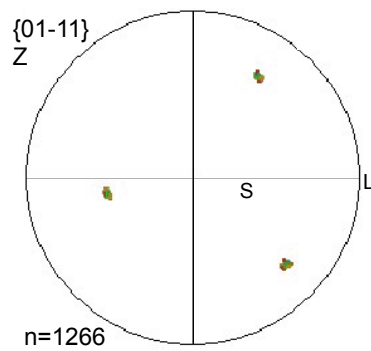

(h)

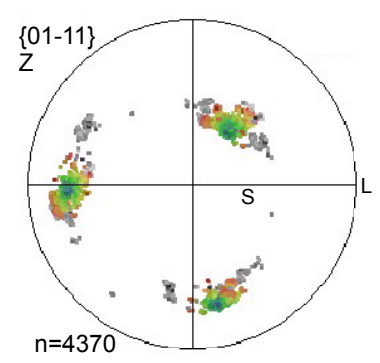

(d)

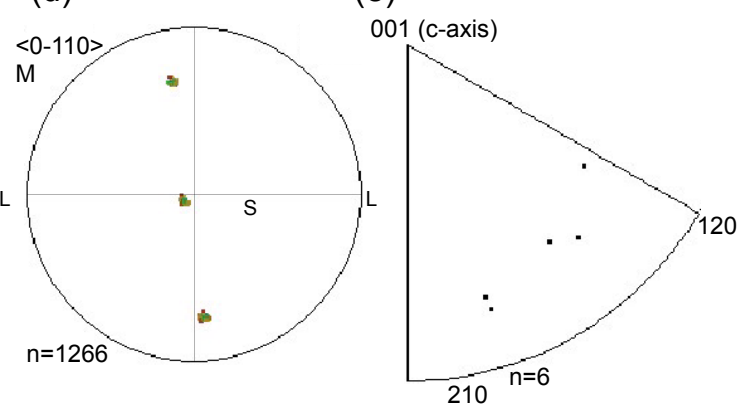

(i)

(j)

(e)

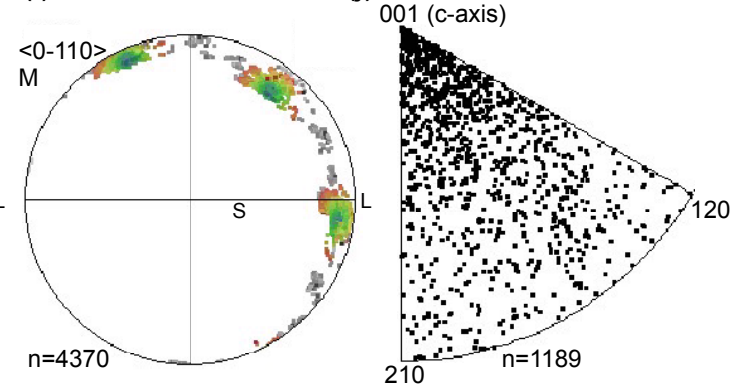

Figure 10 


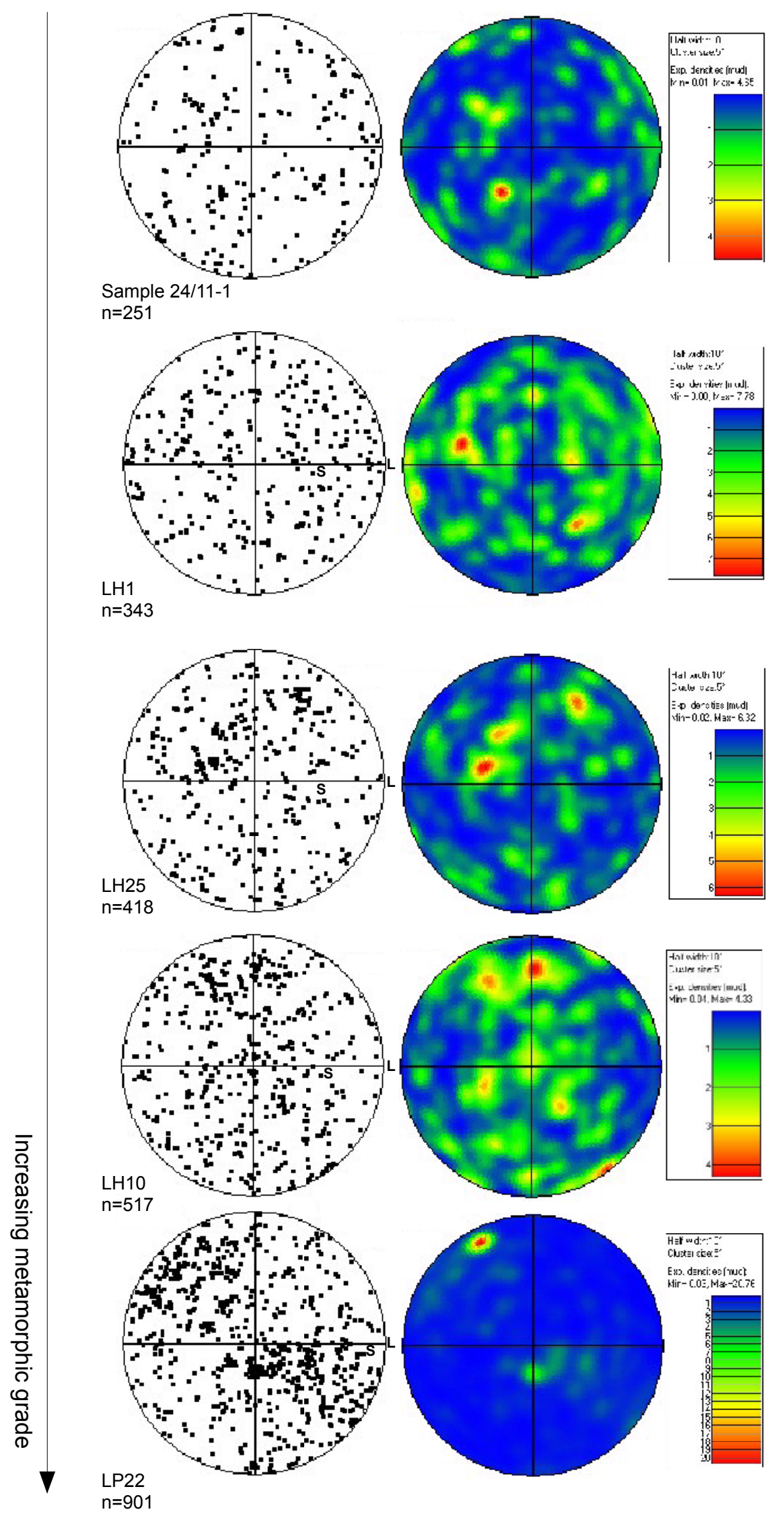

Figure 11 
(a)

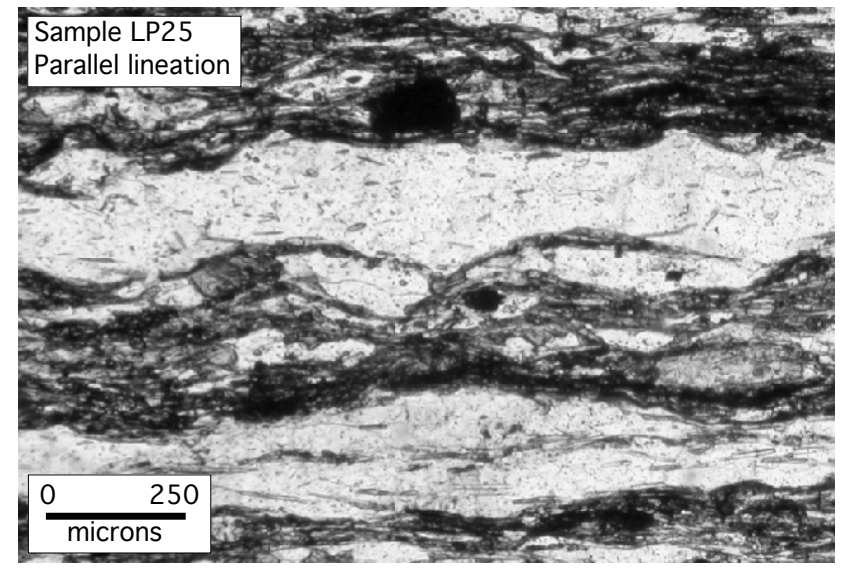

(b)

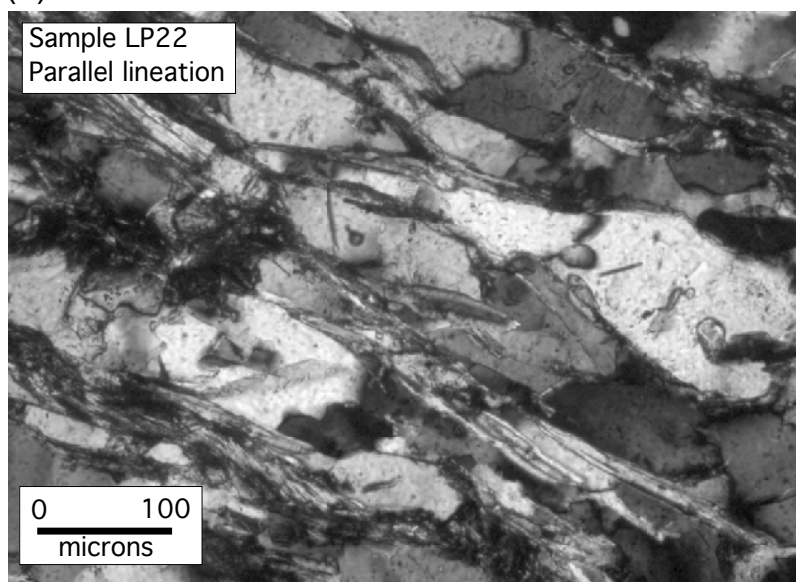

Figure 12

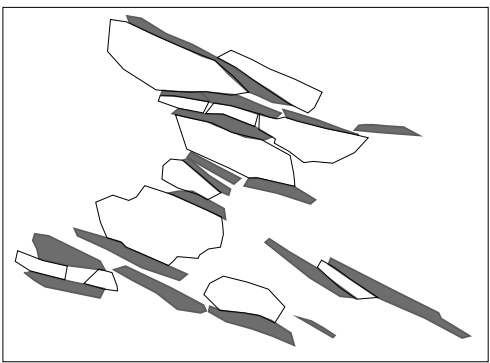


(a)
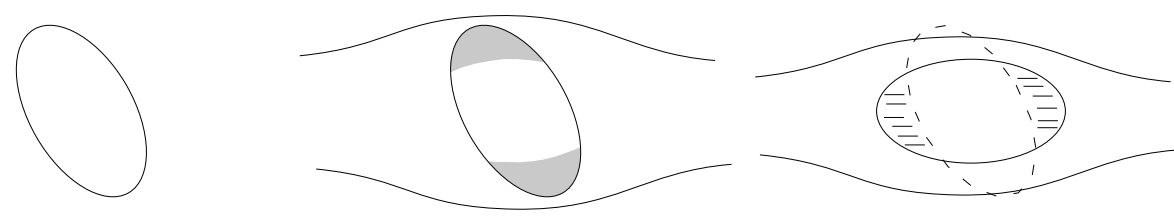

(b)
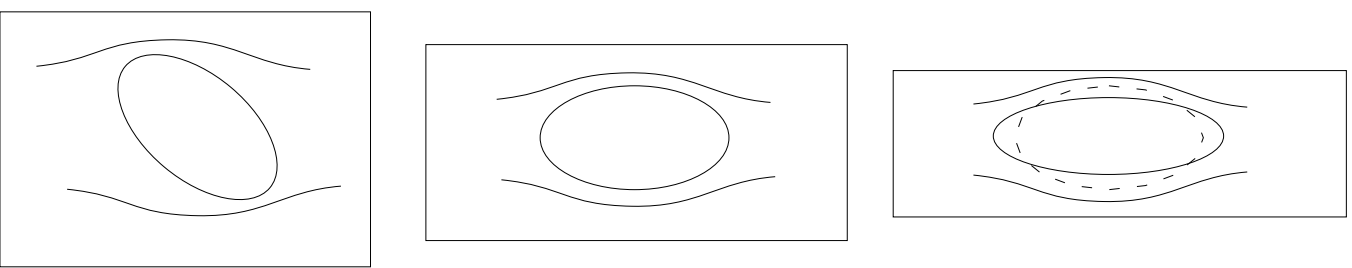

(c)
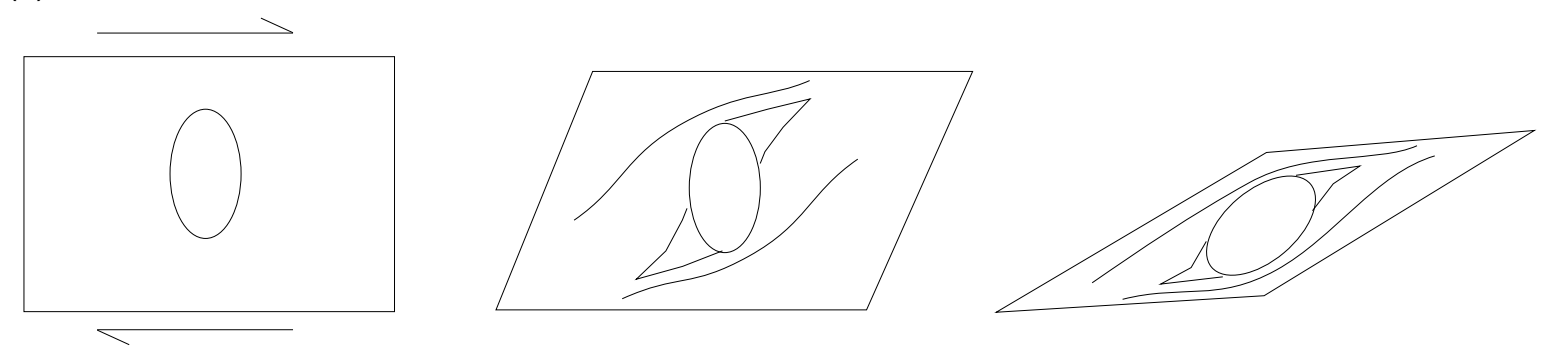

(d)

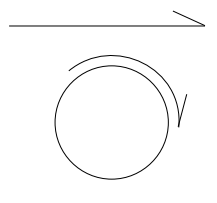

Figure 13 

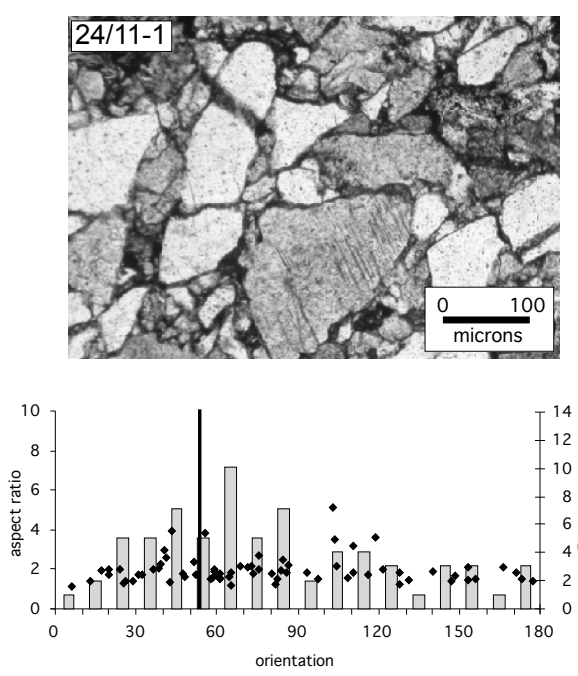
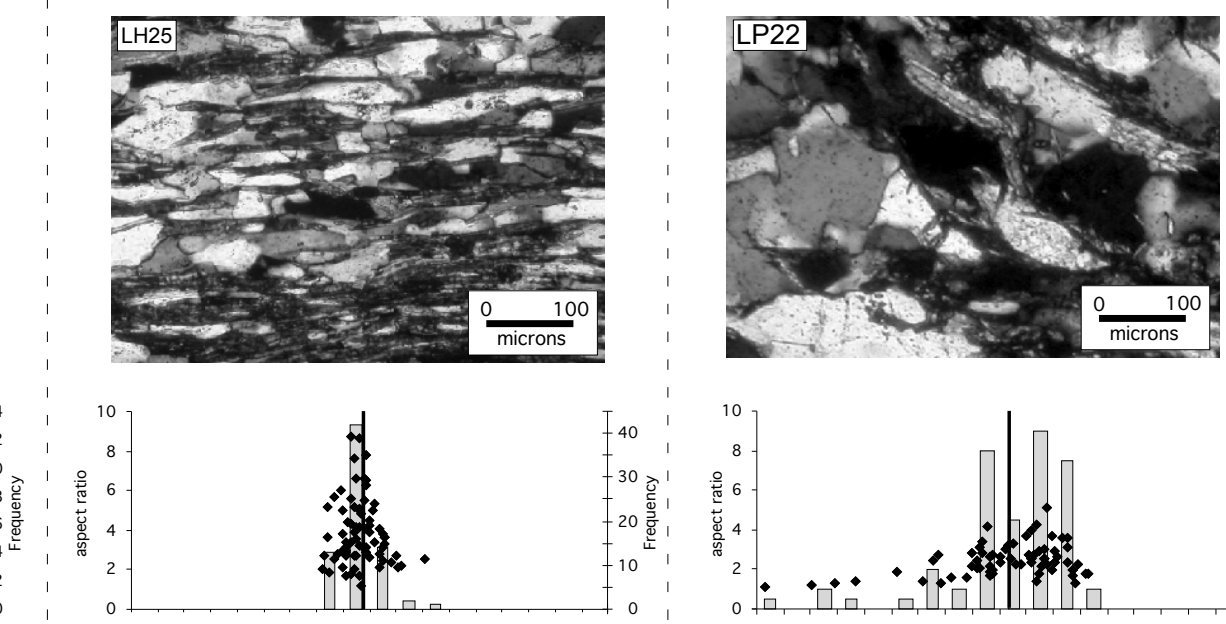
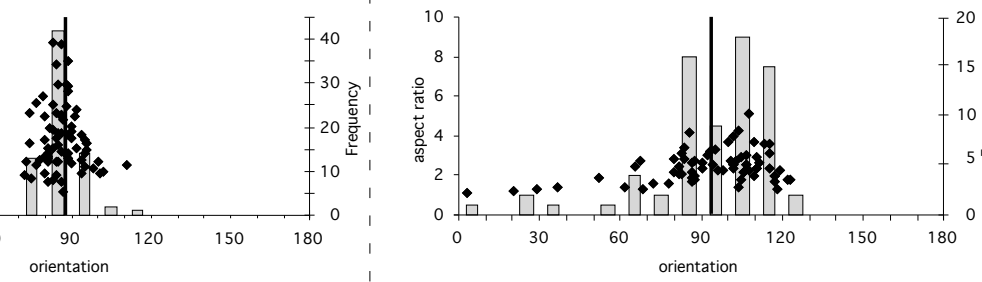

180

SPO

intensity

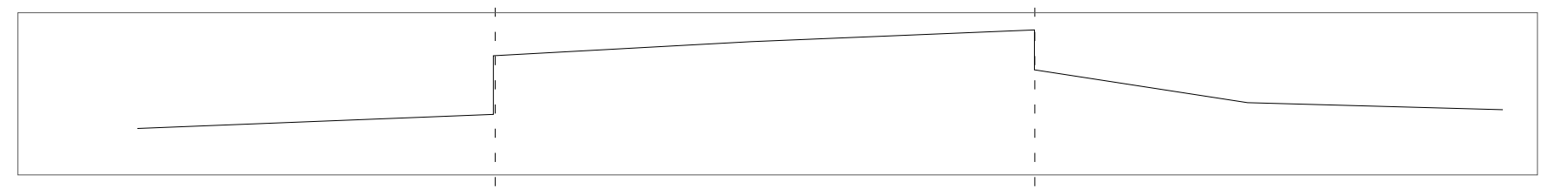
ratio

Average white mica grain size (numbers indicate grain count of white mica per $\mathrm{mm}^{2}$ of thin section)

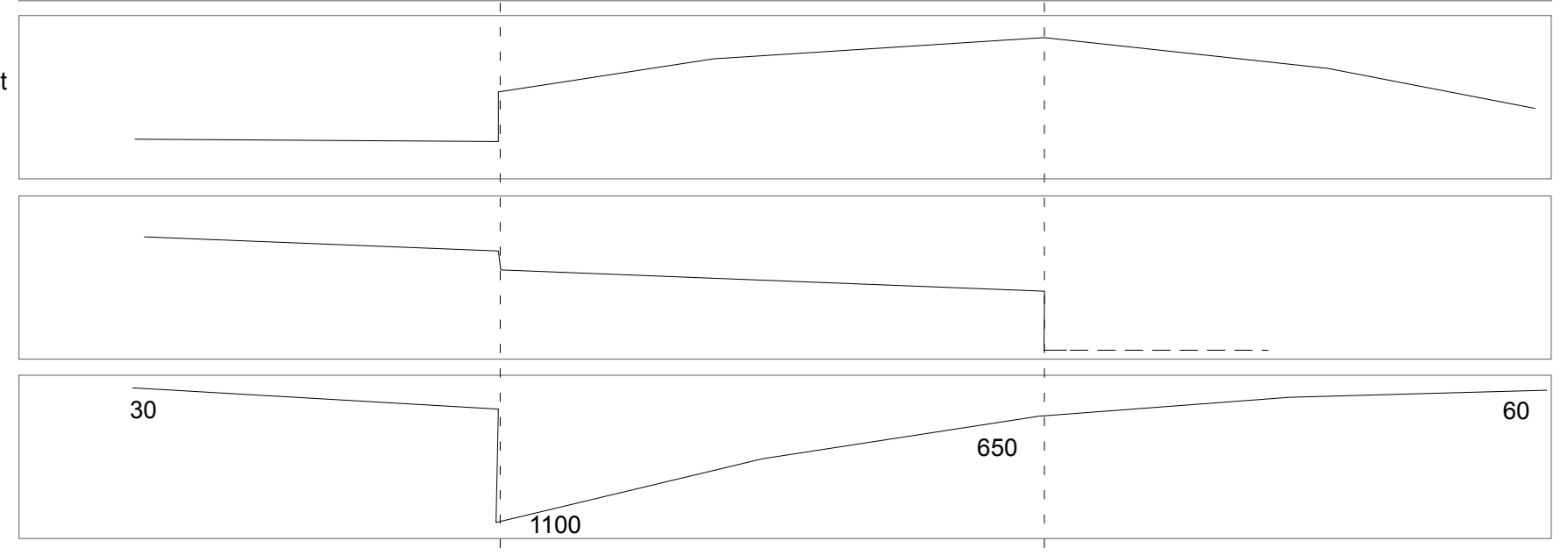

$F_{1}$ folding and related strain.

Solution transfer of quartz, recrystallisation of white mica.

Quartz and white mica SPO defines composite $S_{0}-S_{1}$ foliation.
$\mathrm{F}_{2}$ folding and crenulation.

Segregation of quartz-rich and mica-rich layers

Recrystallisation of quartz, reduction in quartz aspect ratio, reduction in SPO intensity.

Figure 14 
(a)

Lake Hawea transect

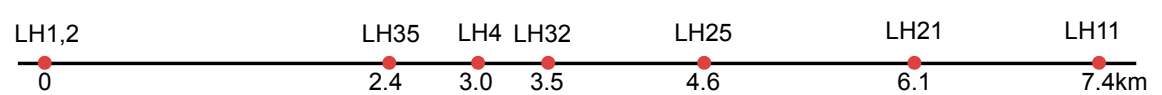

Foliation

Folds

Textural zone

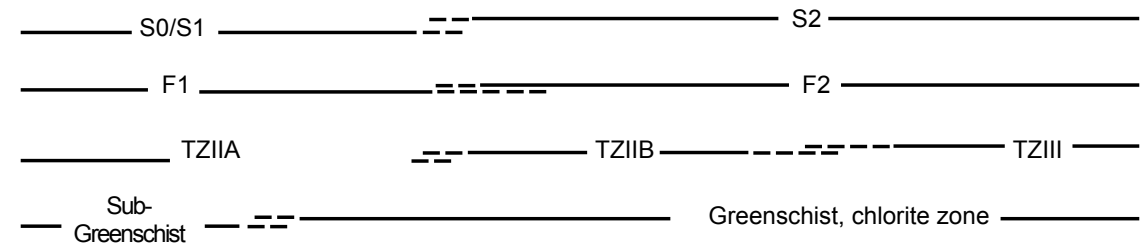

Metamorphic facies - Greenschist Dynamic recrystallization

Deformation mechanism of quartz Dissolution-precipitation creep

(b)

Lindis Pass transect

$\underbrace{24 / 11-1}_{0} \begin{array}{rrrrrr}24 / 11-4 & \text { LP8 } & \text { LP9 } & \text { LP11 } & \text { LP14LP18 } & \text { LP19 }\end{array} \underbrace{\text { LP22 }}_{63}$

Foliation

Folds

Textural zone

Metamorphic facies

Deformation mechanism of quartz


creep

Table 1 